\title{
EFFECTS OF EXPOSURE TO THIN MEDIA IMAGES: EVIDENCE OF SELF-ENHANCEMENT AMONG RESTRAINED EATERS.
}

By

\author{
Jennifer S. Mills
}

\begin{abstract}
A thesis submitted in conformity with the requirements for the degree of Ph.D. Graduate Department of the Department of Psychology University of Toronto
\end{abstract}


Acquioitions and Bibliographic Services

395 Wellington Street Ottawa ON K1A ONA Canada
Bibliothèque nationale du Canada

Aoquisitions of services bibliographiques

395, ne Wellington Ottawa ON KIA ON4 Canada
Your in vares ritrence

our ins nowerdirence
The author has granted a nonexclusive licence allowing the National Library of Canada to reproduce, loan, distribute or sell copies of this thesis in microform, paper or electronic formats.

The author retains ownership of the copyright in this thesis. Neither the thesis nor substantial extracts from it may be printed or otherwise reproduced without the author's permission.
L'auteur a accordé une licence non exclusive permettant à la Bitliothèque nationale du Canada de reproduire, prêter, distribuer ou vendre des copies de cette thèse sous la forme de microfiche/film, de reproduction sur papier ou sur format électronique.

L'auteur conserve la propriété du droit d'auteur qui protège cette thèse. $\mathrm{Ni}$ la thèse ni des extraits substantiels de celle-ci ne doivent être imprimés ou autrement reproduits sans son autorisation. 
Effects of exposure to thin media images:

Evidence of self-enhancement among restrained eaters.

\author{
Ph.D., 2001 \\ Jennifer S. Mills \\ Department of Psychology \\ University of Toronto
}

It is a commonly held belief in the eating disorder literature, as well as in society at large, that the media's focus on slimness contributes to eating pathology. However, previous research on the relation between media exposure and eating disorder symptomatology has produced dramatically mixed findings. The effects of viewing media-portrayed idealized body images on eating behaviour, self-esteem, body image. and mood among restrained and unrestrained eaters were examined in three experimental studies. Study I found that restrained eaters (i.e., chronic dieters), but not unrestrained eaters, reported feeling thinner following exposure to slim models. Restrained eaters rated both their ideal and current body sizes as smaller and ate more following exposure to idealized body images. It is suggested that restrained eaters are susceptible to a "thin fantasy" brought about by viewing ideal body images. Study 2 found that strengthening thinness-attainability beliefs further enhanced the "thin fantasy" exhibited by restrained eaters following exposure to idealized body images. It appears that, following exposure to ultra-slim models, restrained eaters feel inspired by such images and experience a shift toward feeling thinner. The perception of thinness as attainable (through dieting) may facilitate inspiration by thin, idealized body images, thus explaining the observed 
differences between restrained and unrestrained eaters. Study 3 found that after receiving threatening weight-related information from the experimenter, restrained eaters rated their current body size, ideal body size, and the discrepancy between the two measures as smaller. In conclusion, the present set of findings suggests that dieters self-enhance after looking at thin media images due to inspiration. However, there may be other reasons why restrained eaters self-enhance, including defensiveness when negative feedback can be discounted. These results are considered in the context of literature on restraint theory. social comparison, body image, and eating disorders. The complexities of the media's role in the development and maintenance of body dissatisfaction and dieting behaviour are discussed. 


\section{Acknowledgements}

I gratefully acknowledge my thesis supervisor, Dr. Janet Polivy, for her tireless guidance and support, and my thesis committee, including Drs. Peter Herman and Patty Pliner, for their constructive criticism during the completion of this dissertation research. I thank my external thesis examiners, Drs. Alison Chasteen and Fred Boland. for their time and effort toward the completion of my thesis appraisal and defense.

I also thank Poppy Lockwood. Traci McFarlane, Randi McCabe, Deborah Roth. Dana Kahan, Yolanda Martins, Heather Brock, Michele Boivin, and Lenny Vartanian for their valuable contribution to these research projects in their planning and analysis stages. The enthusiastic help from Yarla Rabelo in assisting with data collection in study 3 is gratefully acknowledged.

Brent, your unwavering encouragement is deeply felt and much appreciated. 


\section{Table of Contents}

\section{GENERAL INTRODUCTION........................................... 1}

Correlational Studies Examining the Relation between

Media-Portrayed Idealized Body Images and Eating Pathology...... 3

Experimental Studies of the Effects of Idealized Body Images on Mood and Body Dissatisfaction ................................5

Summary of Research Examining the Relation between Media and Various Parameters of Eating Pathology in Women ............9

Media Images and Social Comparison Theory................... 10

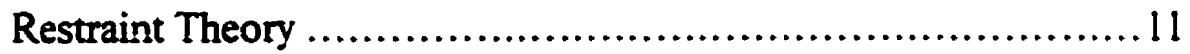

STUDY 1 [............................................................... 12

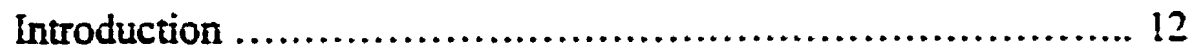

Method ......................................................... 16

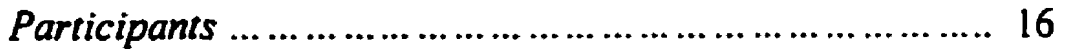

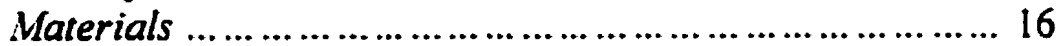

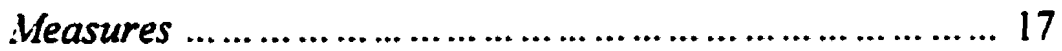

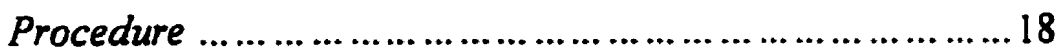

Results .......................................................21

Discussion ...................................................25

STUDY 2 [..............................................................27

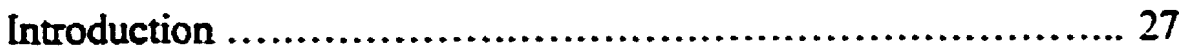

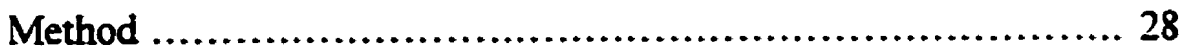

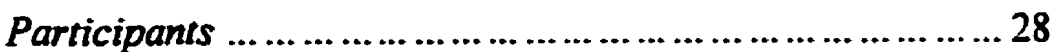

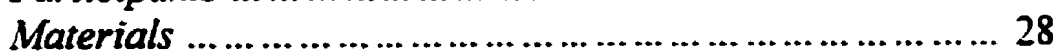

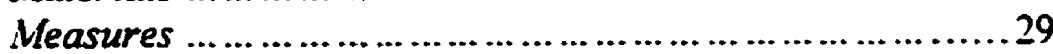

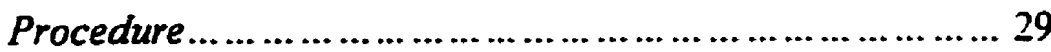

Results ....................................................... 30

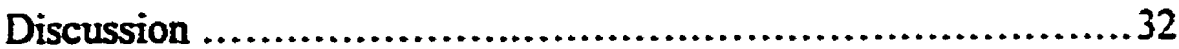




\section{Table of Contents continued}

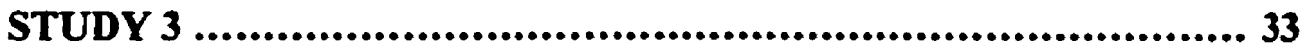

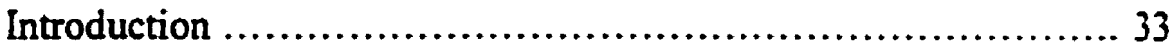

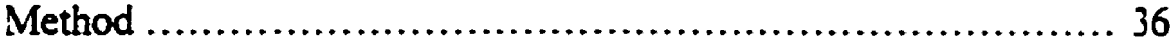

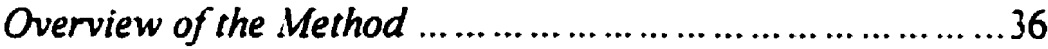

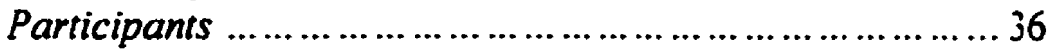

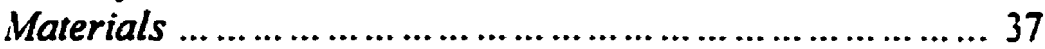

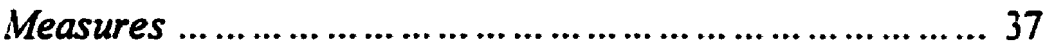

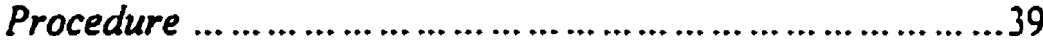

Results...................................................... 41

Discussion .................................................... 46

GENERAL DISCUSSION ................................................ 49

Conclusions .................................................... 52

Limitations and Directions for Future Research ................... 54

\section{REFERENCES}

\section{TABLES}




\section{List of Tables}

Table l

Mean Appearance State Self-Esteem. Current Body-Size Perception, Ideal Body-Size Perception, and Intake as a Function of Restraint and Ad Type.

\section{Table 2}

Mean Anxiety, Depression, Total Negative Affect. Appearance State Self-Esteem. and Current and Ideal Body-Size Perceptions as a Function of Thinness-Attainability Beliefs. and Ad Type among Restrained Eaters.

Table 3

Number of Participants Requesting Participation in Diet Program as a Function of Ad Type and Restraint.

Table 4

Mean Appearance State Self-Esteem, and Current and Ideal Body-Size Perceptions (with standard errors in parentheses) as a Function of Threat Condition and Restraint.

Table 5

Number of Participants Requesting Participation in a Diet Program as a Function of Threat Condition and Restraint. 
Effects of exposure to thin media images:

Evidence of self-enhancement among restrained eaters.

It is a commonly held belief in the eating disorder literature, and in society at large, that the media's focus on slimness contributes to eating pathology (e.g.. Garner \& Garfinkel, 1982; Gordon, 1988; Stice \& Shaw, 1994). According to the sociocultural model, eating disorders are a product of the intense pressure on women in our society to attain a thin body (Striegel-Moore. 1993; Wilson \& Eldredge, 1992), an over-adaptation to a cultural norm rather than a discrete psychopathology (Stice \& Shaw. 1994). While this view oversimplifies the issues and pathology inherent in eating disorders, pressure on women to achieve a thin body shape does seem to contribute to the prevalent problem of body dissatisfaction and disordered eating.

Perhaps the most potent carrier of the idealized thin body image (i.e., the "thinideal" as it is frequently termed) is the mass media (Striegel-Moore. Silberstein. \& Rodin. 1986). Correlational studies demonstrate an association between exposure to media containing idealized body images and eating disorder symptomatology. Such indirect evidence for the role of the media in the development and maintenance of eating disorders comes from numerous studies. The increase in the diagnosis of eating disorders during the last few decades (Szmukler, McCance, McCrone, \& Hunter, 1986; Pyle. Halvorson. Neuman, \& Mitchell, 1986) has been paralleled by a decrease in the size of the media-portrayed thin body for women. While there has been a trend toward a thinner frame, at the same time the bust-to-waist ratios for actresses and models, as seen in 
women's magazines, have steadily increased over the past three decades, reflecting a trend toward a slimmer, yet still curvaceous figure as "ideal" for women (Barber. 1998; Silverstein. Perdue. Peterson, \& Kelly, 1986; Singh. 1993; Spitzer. Henderson. \& Zivian. 1999). Playboy centerfolds and Miss Americas` weights have decreased markedly since the 1950s (Garner. Garfinkel, Schwartz, \& Thompson, 1980; Spitzer et al.. 1999; Wiseman, Gray, Mosimann. \& Ahrens, 1992). The apparent rise in eating disorders has also coincided with an increase in the number of articles on weight-loss and exercise (Garner et al., 1980; Wiseman et al., 1992) and advertisements for diet products (Snow \& Harris, 1986) in popular women`s magazines.

Analysis of the content of popular media reveals their intense focus on the merits of thinness. Even the covers of women's magazines deliver messages about the importance of losing weight. as weil as conflicting messages about weight loss and dietary habits (Malkin, Wornian, \& Chrisler, 1999). An analysis of television situation comedies found that below-average-weight female characters received significantly more positive verbal comments from male characters regarding body weight than did their heavier counterparts (Fouts \& Burggraf, 1999). The same study found that dieting female characters gave themselves significantly more verbal punishment for their body weight and shape than did those less involved in dieting. Andersen and Di[ umenico (1992) found that popular women's magazines contained $10 \mathrm{1} / 2$ times more advertisements and articles promoting weight loss than did popular men`s magazines, perhaps not coincidentally the same sex ratio reported from several sources for cases of anorexia nervosa. These authors posited a dose-response relationship between the sociocultural 
pressures promoting thinness and the incidence of eating disorders in any particular population of women. However. the direction of the relationship between the prevalence of weight loss articles and concern for dieting remains conjectural. It may be that rather than dictating a trend toward concern for weight loss and associated topics. magazine editors are responding to their readership's preference for such articles.

Correlational Studies Examining the Relation between Media-Portrayed Idealized Body Images and Eating Pathology.

Correlational studies typically hypothesize that more media exposure is associated with higher levels of eating pathology. Stice. Schupak-Neuberg, Shaw, and Stein (1994). through structural equation modeling,' Harrison and Cantor (1997), and Botta (1999) have all found a positive relation between media exposure and eating disorder symptomatology. Harrison (1997) found that attraction to thin media personalities was related to eating disorder symptoms. Tiggeman and Pickering (1996) found no correlation between the total amount of television viewing and eating disorder symptomatology, but did find a correlation between program type and eating disorder symptoms. Specifically, amount of time spent watching soaps, movies. and (negatively) sport predicted body dissatisfaction, and the watching of music videos predicted drive for thinness. On the other hand, a study by Cusumano and Thompson (1997) failed to find

' Structural equation modeling employs multiple simultaneous regression analyses in order to test "paths" between observed and/or latent variables. The Stice et al. (1994) study involved no manipulation of variables; thus conclusions should be limited. at most. to the discussion of the relation between two variables. 
any relation between naturally occurring media exposure and indices of body image. eating dysfunction, and self-esteem among college females, whereas it did find that internalization of societal standards of attractiveness correlated with eating disorder symptoms. Borzekowski, Robinson, and Killen (2000) also found no relation between total media use and eating pathology, but reported that exposure to music videos was related to the importance of weight concerns.

Further indirect evidence for the sociocultural model of eating derives from the finding that female bulimics show a greater internalization of the idealized body image than do nonbulimics (Irving, 1990; Kendler, MacLean. Neale. Kessler. Heath. \& Eaves. 1991). Bulimics also score higher than do control subjects on the Drive for Thinness subscale of the Eating Disorder Inventory (Gamer, Olmsted. \& Polivy, 1983) and endorse sociocuitural mores regarding the desirability of a thin body more than do chronic dieters or control subjects (Mintz \& Betz, 1988), confirming that it is wanting to the thin. idealized body size and shape that causes eating problems. Moreover, females with eating disorders are less likely to adopt a critical stance with respect to societal ideals of thin body shapes than are normal, non-disordered women (Murray. 1999). Patients* critical ability was also significantly negatively related to the duration of their disorder (Murray, 1999).

In sum, then, the correlational evidence does point to a positive relation between mass media exposure and eating disorder symptomatology. However, the direction of the association between exposure to media body images and drive for thinness remains conjectural. It is certainly plausible that those women who are concerned with their 
appearance are the same women who choose to read fashion and beauty magazines. Perhaps exposure to idealized images creates a concern about one's own body image. but it might also be the case that concern about one's own body image leads to greater exposure to media images. Perhaps the secular trends in media content reflect. rather than produce, the secular trends in body dissatisfaction. Lastly, it is possible that some individual characteristic leads one to both eating disorders and the consumption of mass media (e.g., low self-esteem).

\section{Experimental Studies of the Effects of Idealized Body Images on Mood and Bodv} Dissatisfaction.

A number of studies within the last decade have attempted to demonstrate that acute exposure to idealized thin body images plays a causal role in the development of negative consequences for women, such as lowered seif-esteem and heightened body dissatisfaction. One way in which exposure to idealized thin body images is theorized to affect women's self-evaluation is by increasing body-image distortion. When confronted with images of ultra-slim models, even normal-weight women who compare themselves to the models may overestimate their own size as a result of a negative contrast effect. leading in some cases to dieting and, in extreme (and susceptible) cases, eating disorders. Hamilton and Waller (1993) exposed eating-disordered and non-eating disordered women to magazine pictures containing thin body images and neutral images. After looking at each set of pictures, participants estimated the sizes of their own waist, chest. and hips. The experimenter later measured subjects' objective size and a body perception index (i.e., body-size overestimation) was calculated. Eating-disordered and normal/control 
women responded differently to the two types of images. Anorexic and bulimic women who viewed the thin-body photographs showed a significant increase in their body-size overestimation compared to when they looked at neutral images. On the other hand. the type of photograph seen did not affect control subjects' body-size estimates. While bodyimage distortion is not, in and of itself, a diagnostic criterion for zating disorders. particularly because of its high prevalence in normal women (Hsu \& Sobkiewicz. 1991). the Hamilton and Waller (1993) study as well as a similar study by Waller, Hamilton. \& Shaw (1992). provides evidence that eating-disordered women may be particularly vulnerable to any body-size overestimation brought about by exposure to idealized body images.

Irving (1990) showed slides of thin, average, and oversize models from popular women's magazines to female subjects with varying levels of bulimic symptoms. A noexposure control group was not shown any stimuli prior to completing the various selfreport measures. Subjects exposed to the thin fashion models exhibited lower levels of self-esteem than did subjects exposed to either average or oversize models. but this effect was actually due to the increased self-esteem and weight satisfaction of subjects shown average and larger models. Contrary to the author's main prediction that women displaying high levels of bulimic symptoms would be more affected by the thin body images than would individuals exhibiting few bulimic symptoms, exposure to the slides of the thin models resulted in self-evaluations equal to those of the no-exposure control group, regardless of subjects' level of self-reported bulimic symptoms. These results were interpreted by Irving as possibly due to a "ceiling effect" (more correctly, a "floor 
effect"); that is, the chronically low self-evaluations found in high bulimic-symptom subjects make it difficult for external stimuli to significantly lower their self-evaluations any further. Alternatively, it may simply be that level of bulimic symptomatology is unrelated to any adverse effects of exposure to ideal body images on self-evaluations. One acknowledged limitation of the Irving (1990) study is the fact that the weight and attractiveness of the target models were confounded. Irving suggested that future studies should match stimulus materials for attractiveness and appearance-related features. but this may not be possible; some evidence suggests that subjects rate thin models as more attractive than oversize models even when they are matched on other attractivenessrelated cues (Stice \& Shaw, 1994). Methodological flaws notwithstanding, the lack of any significant difference between the control group and the thin-image groups means that the Irving study failed to show any adverse effects of idealized body images on either weight satisfaction or self-esteem. This failure ran contrary to one of the author's main predictions but was not acknowledged as such. ${ }^{2}$ Indeed, it can be concluded from the Irving study only that exposure to the average and oversize models raised both the weight satisfaction and self-esteem of the participants. Similarly, Champion and Furnham (1999) found no adverse effect of media exposure on eating disorder symptomatology, and Seddon and Berry (1996) found no effect on self-esteem of viewing idealized body

2 Because responses following exposure to the thin models were significantly lower than were those elicited by average-sized and large models, Irving interpreted this as a "lower" self-evaluation, despite the lack of difference between exposure to thin models and no exposure at all. 
images in television commercials.

Other experimental studies have found adverse effects of media exposure on eating pathology and its correlates. Stice and Shaw (1994) demonstrated that. in females. a mere three minutes of exposure to pictures of ultra-thin models induced feelings of depression, unhappiness, shame, guilt, stress, and body dissatisfaction, as well as decreased confidence. Furthermore, negative affect. body dissatisfaction. and subscription to the "thin-ideal" each had a unique predictive effect on bulimic symptoms. These findings refute those of Irving (1990) and support the sociocultural model of eating disorders. Contrary to the authors' predictions, though, exposure to idealized bodies did not result in increased feelings of anxiety, nor did it have a significant effect on idealbody-stereotype endorsement. As in the Irving (1990) study, the Stice and Shaw study confounded the thinness and attractiveness of the models; subjects rated the thin models as significantly more attractive than the average-weight models. Also, no behavioral measure of eating was taken; there was an exclusive reliance on self-report data with respect to bulimic symptomatology.

Heinberg and Thompson (1995) demonstrated that females scoring above the median splits on dispositional body image disturbance and sociocultural awareness/internalization felt more depressed and were more dissatisfied with their bodies following exposure to commercials containing thin and attractive images than they had beforehand. Ogden and Mundray (1996) found that both men and women reported feeling greater body dissatisfaction after viewing pictures of same-sex thin idealized bodies than after viewing heavy bodies, with this response being greater in females than 
in males. Shaw (1995) showed that female adolescents report increased body dissatisfaction after viewing media-portrayed idealized body images. Finally. Pinhas. Toner. Ali. Garfinkel, and Stuckless (1999) found that exposure to temale fashion models in magazine pictures resulted in increased depression and anger.

The research literature also contains a handful of (less frequently cited) studies showing positive effects of exposure to idealized body images. Myers and Biocca (1992) examined the capacity of television advertising and programming to influence a woman's perception of her own body. They found that, contrary to their predictions, viewing commercials containing idealized body images resulted in reduced body size overestimations. Mills (1996) found that females had higher appearance state self-esteem following exposure to magazine advertisements featuring thin media images than to those featuring either products only or attractive facial images. In addition, a study by Henderson-King and Henderson-King (1997) found that. in general, exposure to idealized body images did not have an effect on subjects' body esteem. Dispositional selfmonitoring, however, moderated the effects of idealized body images on women. High self-monitors who were exposed to idealized body images were more positive about their own physical condition than were low self-monitors.

Summary of Research Examining the Relation Between Media and Various Parameters of

\section{Eating Pathology in Women}

The combined correlational and experimental literature thus shows dramatically mixed results. Correlational studies seem to demonstrate a reliable association between exposure to idealized body images and eating disorder symptomatology. Some 
experimental studies suggest that exposure to media projecting idealized body images has either an adverse main effect on female viewers or an interactive effect with body-image disturbance. Other studies fail to demonstrate any significant effect in non-eatingdisordered women, and still others find unexpected positive effects (i.e., selfenhancement) following such exposure. Finally, there is the obvious fact that young women go out of their way to expose themselves to these images. suggesting that they may not have such adverse effects.

\section{Media Images and Social Comparison Theory}

The relation of the idealized thin body image to self-evaluation in women is frequently conceptualized in terms of a "contrast effect," a tendency to evaluate more negatively one's own appearance after viewing highly attractive individuals (Thorton \& Moore. 1993). Previous research has shown that exposure to highly attractive target persons results in lower ratings of one's own attractiveness than does exposure to unattractive target persons (Cash, Cash, \& Butters, 1983). The reasoning behind contrast effects is derived from social comparison theory: we evaluate ourselves not in absolute terms but in comparison to other people (Festinger. 1954). For example. in the presence of an extremely attractive object, objects of average attractiveness will be rated much less favorably. By the same token, constant exposure to highly attractive, thin female images in the mass media would be expected to produce a high "adaptation level" (Helson. 1964) and result in lowered assessments of the attractiveness of more realistic, "average" females (Kenrick \& Gutierres, 1980), including oneself. Martin and Kennedy (1993) and 
Richins (1991) have also discussed how social comparison processes may help to explain reactions to advertised idealized images.

In contrast to social comparison theory, Tesser's self-evaluation maintenance model (Tesser, 1988) predicts a positive self-evaluation (i.e., self-enhancement) following exposure to a highly attractive target. In this model, the goal is not accurate selfevaluation but the preservation of self-esteem. There are other reasons why selfenhancement can occur. For instance, viewing a highly attractive model may have inspirational effects on an individual, resulting in a positive shift in self-evaluation (see Collins, 1996). Lockwood and Kunda (1997) have demonstrated experimentally the inspirational effects of academic "superstars" on university students. Presumably. a highly successful target evokes a salient "possible self" that is integrated into one's current self-image. Likewise, photographs of thin attractive magazine models could make a woman temporarily feel better about herself because they bring to mind a thinner. more attractive possible version of the self. Recall that Mills (1996) found that females had higher appearance state self-esteem following exposure to thin media images than to product-only or attractive facial images. This theory is surely not lost on fashion and beauty magazine editors, or the diet industry, but is frequently neglected in studies based on the sociocultural (i.e., negative contrast) model of eating disorders.

\section{Restraint Theory}

The dramatically mixed findings in the effects of exposure to idealized body images on eating, mood, and body image parameters lead us to inquire about individual factors in the effect of media exposure. Maybe not all women respond to media images 
the same way. That is, personality may moderate the effects of exposure to thin media images. One individual difference variable already found to produce behavioural eating differences in response to thin media images in restraint (Strauss, Doyle, \& Kreipe. 1994). Restrained eating (i.e., dieting) can be defined as an attempt to restrict one's food intake with the intent of decreasing or maintaining one's weight. While dieting may be considered normative, particularly for young women (e.g., Polivy \& Herman. 1995). dieting often has significant adverse health effects, including increased emotional lability. lowered self-esteem, preoccupation with food, susceptibility to binge eating, and weight fluctuations (see Polivy \& Herman, 1987). We would expect restrained eaters to respond differently to exposure to idealized body images than unrestrained eaters do because restrained eaters have heightened body dissatisfaction and weight/shape concerns and are in the process of attempting to change their weight and'or shape. In other words. weight and shape are personally relevant for restrained eaters. Due to broad societal and cultural pressures for thinness, weight and shape may be personally relevant for unrestrained eaters as well. but not to the same extent as for restrained eaters.

\section{Study 1}

Study $l$ in the present set of studies investigated the role of dietary restraint as a possible personality moderator of image exposure effects. According to the spiral model" of chronic dieting and eating disorders proposed by Heatherton and Polivy (1992). dieters engage in negative self-evaluations when confronted with slim body images. Because they feel that they do not live up to their high standards for body weight and shape, dieters initiate a series of unsuccessful diets to achieve their goal of thinness. 
and in doing so, spiral into increased negative affect and body dissatisfaction. reduced self-esteem. and increased susceptibility to dietary disinhibition and overeating. Nondieters, who show less concern for weight loss and thinness than do dieters, presumably do not feel as threatened by a perceived discrepancy between their own bodies and the ideal physique.

Strauss et al. (1994) found that visual images of thin models in diet-related commercials produced disinhibited eating among restrained eaters. They proposed that the thin images produced ego threats in the dieters; the disinhibiting effects of ego threats on the eating behavior of restrained eaters have previously been demonstrated (Heatherton, Herman, \& Polivy, 1991). In the Strauss et al. (1994) study, attempts to "reinhibit" dieters who had been preloaded and disinhibited (by watching a sad movie) by exposing them to a diet-oriented commercial resulted instead in dieters eating more than did those shown either no ad or a neutral ad. The authors concluded that the thin media images in the diet ads functioned as an ego threat. unleashing further disinhibited eating among dieters. However, since the Strauss et al. (1994) study did not measure the effects of thin-image exposure on indices of ego threat/distress (e.g., depression, anxiety, selfesteem). the conclusion that the dieters who saw the diet commercial experienced ego threats remains speculative.

In a similar study by Seddon and Berry (1996), restrained and unrestrained participants saw videotaped television advertisements containing either stereotypical idealized images of women or matched advertisements containing neutral images. Exposure to ads featuring thin idealized body images caused restrained eaters, but not 
unrestrained eaters. to increase food consumption in a subsequent ad lib taste task. Contrary to the authors' predictions, dieters' self-esteem was not worsened by viewing thin bodies. Thus, no conclusions were reached as to why the restrained eaters' intake was disinhibited.

As a whole, the experimental literature on the effects of exposure to media portrayals of slender female bodies on eating, mood, body-image, and self-image suggests that for dieters at least, viewing slim images may lead to dysphoria. worsened bodyimage, and ego-threat-induced disinhibited eating. However, because there is no concomitant evidence in the eating studies that participants actually feel worse about themselves or are "threatened," there is a possible alternative explanation. Several of the experimental exposures to thin images produced positive effects on self-image. suggesting that the overeating by dieters could conceivably reflect positive affect. Positive affect, like negative affect, may disinhibit eating (Cools, Schotte. \& McNally. 1992). Finally. feeling thin may itself influence food intake. Thinking of oneself as already thin, and therefore not needing to restrict, may elicit disinhibited eating.

The notion that exposure to idealized images might produce positive affect in viewers is at first difficult to imagine for those who have come to take the social comparison or negative contrast assumption for granted. A positive response to idealized images, however, might help to explain the otherwise paradoxical fact that people seem to enjoy viewing idealized images, and voluntarily do so: indeed. they are willing to pay to do so, as the magazine. television. and film industries can attest. 
The first study therefore sought to replicate and extend the findings of Strauss et al. (1994), and Seddon and Berty (1996) by exploring whether exposure to thin body images results not only in disinhibited eating, but also in changes in mood and body image among restrained eaters, but not unrestrained eaters. It was hypothesized that restrained eaters, who are concerned about their weight and shape, would eat more following exposure to magazine ads portraying thin female bodies than after seeing magazine ads featuring either "plus-size" women's bodies or neutral (product-only) images. Plus-size female models were included as a comparison group in order to demonstrate that it is specifically thin female body images and not female body images in general that elicit disinhibited eating among dieters. If Strauss et al. (1994) are correct. overeating among restrained eaters should be mediated by ego threats, which should produce an increase in restrained eaters ${ }^{\circ}$ current and ideal body-size estimates, and a worsening of mood and self-esteem. However, restrained eaters may exhibit the selfenhancement effect found for participants overall in Mills (1996). Because of their intense concern with weight and shape, dieters may be particularly susceptible to the inspiring effects of viewing idealized body images. If so, restrained eaters should respond to idealized body images as did high self-monitors in Henderson-King and HendersonKing (1997) and feel better about their own appearance following exposure to thin body images. Their increased eating would thus reflect feeling thin (and therefore reduced concerned with restricting intake) rather than negative affect. 


\section{Method}

\section{Participants}

Ninety-eight female undergraduate students between the ages of 18 and $25 \underline{M}=$ 19.72. $\underline{S E}=.14)$ enrolled in Introductory Psychology at the University of Toronto at Mississauga volunteered to participate. Students participated in the study to partially satisfy course requirements or they were paid \$7.00. APA ethical principles (American Psychological Association, 1992) were applied to all participants, including institutional approval. informed consent, not offering undue inducement for research participants, no unnecessary deception, informed sharing and utilizing of data. and providing participants with information about the study. In order to calculate BMI, height and weight were collected from all participants except for four participants who refused to be weighed by the experimenter. ${ }^{3}$ A one-way ANOVA reveaied no significant differences between experimental conditions with respect to BMI. However, restrained eaters overall had a higher $\mathrm{BMI}(\underline{\mathrm{M}}=25.83, \underline{\mathrm{SE}}=.93)$ than did unrestrained eaters $(\underline{\mathrm{M}}=21.72, \underline{\mathrm{SE}}=.43)$. $\underline{F}_{(1.94)}=18.69, \mathrm{q}<.001$.

\section{Materials}

Magazine Advertisements. The thin-body ads were selected by a group of researchers and showed a full-body photo of a female model judged to be attractive and very thin. The plus-size-body ads were selected by a team of researchers and had to show a full-body photo of a female model judged to be attractive and moderately heavy. These

${ }^{3}$ The conditions of the four participants who refused to be weighed were restrained/large bodies, restrained/product-only, unrestrained/thin bodies, and unrestrained/ product-only. 
ads were all taken from the magazine "Mode," which is a high-quality fashion magazine featuring plus-size models. The product-only ads showed no model, either male or female. All ads had to be judged to be colorful and generally attractive. Consideration was given to choosing ads for the body conditions featuring models who differed from one another in terms of complexion, hair color, and race, and product-only ads depicting products similar to those in the body ads.

\section{Measures}

Dietary Restraint. The Restraint Scale (Polivy, Herman, \& Howard. 1988) consists of 10 scored items (e.g., "How often are you dieting?") and assesses frequency of dieting, attitudes toward eating, and weight fluctuations. This measure has satisfactory test-retest reliability and construct, criterion, and concurrent validity (Heatherton. Herman, Polivy, King, \& McGree, 1988). The scale also includes five unscored items: age. sex, height, weight, and maximum past weight. Restraint score was used as a subject variable in the present study. Individuals scoring 15 or more were classified as restrained eaters; those scoring 14 or less were classified as unrestrained eaters.

Negative Affect. The Affect Rating Scale (ARS; Atkinson \& Polivy, 1977) is a 66-item scale designed to measure current mood, including level of anxiety (e.g., " I feel nervous"), hostility (e.g., "I feel angry at others"), and depression (e.g., "I feel sad"). Participants indicate on 4-point Likert scale to what extent a statement describes their current feelings. Maximum scores are 76 for anxiety, 76 for depression. and 80 for hostility. 
State Self-Esteem. The Current Thoughts Scale (Heatherton \& Polivy, 1991) is a 20-item questionnaire designed to measure state self-esteem. Participants indicate on a 5point Likert scale how true an item is of them at the moment. The three self-esteem subscales are appearance (e.g., "I feel satisfied with the way my body looks right now"). performance (e.g., "I feel as smart as others") and social (e.g., "I feel that others respect and admire me"). Maximum scores are 30 for appearance, 35 for social, and 35 for performance state self-esteem.

Current and Ideal Body-Size Perception. The present study adapted Fallon and Rozin's (1985) measure of body perception in order to measure current and ideal bodysize perception. Our index consisted of two identical rows of female body silhouettes arranged from thinnest to heaviest (left to right). Participants circled a number on a line (i.e., $1,1.5,2$, etc.) below the female silhouette that best resembled their (1) current bodysize perception among the top row of silhouettes and (2) ideal body size among the bottom row of silhouettes. Participants scores for current and ideal body size perception could range from 1 to 9 and half scores were permitted.

\section{Procedure}

The experiment was presented to subjects as a market research study entitled "The Effectiveness of Advertising." Upon debriefing at the end of the study, no participants revealed knowledge of the true purpose of the study. A single experimenter tested each participant in one-hour sessions between 11:00 a.m. and 6:00 p.m. Participants were seated alone at a table in a private room. After reading and signing a consent form and completing initial mood and hunger ratings, each participant received 12 laminated full- 
page color ads taken from recent issues of popular women's magazines. The ads were presented in counterbalanced order. Participants were randomly assigned to one of three conditions, viewing: ( 1 ) seven ads showing thin bodies plus 5 ads showing no model (product-only filler ads); (2) seven ads showing large bodies plus 5 ads showing no model; or (3) twelve ads showing no model (product-only). Participants were given a bogus "Consumer Research Questionnaire" to complete for each ad and were told that they had 15 minutes to look at and rate the ads. The Consumer Response Questionnaire asked participants to indicate, on 9-point Likert scales. 1) the overall attractiveness of the ad. 2) the attractiveness of the model in the ad (if applicable), 3) the extent to which they see themselves as being similar to the model in the ad (if applicable), 4) the effectiveness of the ad in making them want to buy the advertised product, 5) the age group to which they think the ad wouid appeal, and 6) how good the ad made them feel. Principaily. these questions were asked to increase the credibility of the cover story and to focus participants' attention on the ads. However, similarity ratings were relevant to our hypotheses as derived from social comparison theory and were included in the analyses.

After 15 minutes, the experimenter returned to collect the ads and the completed questionnaires. The experimenter then explained that while she was getting the next part of the experiment ready, if the student was willing to participate, another researcher in the department was conducting a brief questionnaire study on attitudes among female university students. All participants agreed to take part in the second, ostensibly unrelated study. Participants were presented with the state measures of interest to the study (mood, self-esteem, and body-size perception) and were instructed to complete 
them in the order in which they appeared. Participants rang a bell to indicate to the experimenter in the next room when they were finished.

The experimenter returned to the room and placed in front of the participant three plates piled high with three different types of small freshiy-baked cookies (chocolatechip, double chocolate-chip, and oatmeal raisin). The weight of the plates was recorded beforehand. It was explained that a local cookie company had a new brand of cookie dough coming out on the market soon and that they would like to know which one to "push" first in an ad campaign. Participants were provided with a rating sheet for each plate and were instructed to rate the taste of the cookies on a form in terms of how salty. sweet, sour, bitter, good tasting, and likable they were. To boost the cover story. the experimenter told the participant that the plates were arranged in a particular order. that the ratings should be performed in that order, and that they should have a drink of water before tasting the next type of cookie. Participants were told that they should taste as many cookies as were necessary to ensure accurate ratings, but that they should not change their ratings once made. Participants were told that after the ratings of all three types of cookies had been completed, they should help themselves to as many cookies as they wished, as the lab had "tons of them," but they were told not to change their ratings. Finally, the experimenter answered any remaining questions and told participants that she would return in ten minutes. In ten minutes the experimenter returned and collected the plates of cookies and rating forms. She then presented participants with seven more magazine ads to look at and rate on the same forms as earlier. The magazine ads were of the same type that participants saw earlier and consisted of either l) five thin bodies ads 
with 2 control ads, 2) five plus-size bodies ads with 2 control ads, or 3) product-only ads. In this second exposure phase, participants were told to take as long as they liked looking at the ads and to ring a bell once they were done. How long participants chose to look at and rate the ads was recorded.

In the final part of the experiment, the experimenter told participants that she had some more questionnaires for them to complete that were part of the other researcher's study. Participants then completed the personality measure of interest to the experiment (dietary restraint). The experimenter then returned to debrief participants and to probe whether they were aware of the connection between the different tasks, which they were not.

To summarize the procedure, the study was presented to participants as involving three distinct and ostensibly unrelated tasks - two market research investigations and questionnaire data collection. Participants first completed the magazine market research task. Participants completed state questionnaire measures while they believed the second market research task was being prepared (the taste test). The remainder of the questionnaires (trait measures) was given to participants at the end of the study just before debriefing.

\section{Results}

A series of 2-way (Ad Type by Restraint) analyses of variance (ANOVAs) testing the main hypotheses were performed on the dependent measures, including cookie intake.

\footnotetext{
+ The Eating Disorder Inventory (Garner et al., 1983) was also administered at the end of the study, but was not a primary variable of interest.
} 
mood, state self-esteem, and current and ideal body-size perception. Since there were no significant differences with respect to time spent looking at the ads, those data are not considered here further.

Cookie Intake. Our first hypothesis was that restrained eaters' intake would be more likely to become disinhibited following exposure to magazine ads portraying thin female bodies than after seeing magazine ads featuring either "plus-size" women's bodies or neutral (product-only) images. A two-way ANOVA (Ad Type by Restraint) performed on total food intake revealed a significant interaction, $\underline{\mathrm{E}}_{(2.97)}=4.42 . \mathrm{p}<.02$. As is shown in Table 1, restrained eaters ate more in the thin-body condition than in either the largebody or product-only conditions, $\underline{\underline{t}} \mathrm{~s}_{(92)}>1.95 . \mathrm{p}<.05$. Restrained eaters ate nonsignificantly less in the large bodies condition than in the product-only condition. $\mathrm{L}_{92 \mathrm{f}}$ $=1.37, \mathrm{p}>.15$. Unrestrained eaters ate the same amount regardless of ad condition.

Insert Table $\mathrm{I}$ about here

Negative Affect. It was predicted that disinhibited eating among restrained eaters in response to exposure to idealized body images would be associated with changes in mood and/or state self-esteem. Two-way ANOVAs (Ad Type by Restraint) performed on depression, anxiety, and hostility revealed no significant main or interaction effects. Thus, restrained eaters who viewed the thin-body ads did not report more or less negative affect than did those who viewed the large-body or product-only ads. 
State Self-Esteem. Appearance and total state self-esteem were included in the present analyses as a further test to determine how ads influence how participants feel. and to help explain their eating behaviour. The 2-way ANOVAs revealed significant main effects of Restraint on appearance $\left(\underline{E}_{1.97}=14.94 . \mathrm{Q}<.01\right)$ and total $\left(\underline{E}_{(1.97)}=7.62 . \mathrm{g}\right.$ $<.01)$ state self-esteem; restrained eaters had lower appearance and total state self-esteem than did unrestrained eaters. There was a marginal interaction between Ad Type and Restraint on appearance state self-esteem $\left(\underline{E}_{1.97}=3.01, \mathrm{p}<.06\right)$; restrained eaters had higher appearance self-esteem in the thin-body condition $(\underline{\mathrm{M}}=19.00, \underline{\mathrm{SE}}=1.37)$ than in the large-body condition $(\underline{\mathrm{M}}=15.70, \underline{\mathrm{SE}}=1.37)\left(\mathrm{t}_{-92)}=1.79, \mathrm{Q}<.10\right)$ with the neutral condition not significantly different from either the thin- or large-body conditions $(\underline{\mathrm{M}}=$ 17.95, $\underline{\mathrm{SE}}=1.35$ ). There were no differences among unrestrained eaters with respect to appearance state self-esteem.

Current and Ideal Body-Size Perception. Finally, it was predicted that if selfenhancement follows exposure to idealized body images among restrained eaters. dieters should also report improved body image. The 2-way (Ad Type by Restraint) ANOVAs revealed a significant main effect of Restraint on current body size perception, $\underline{F}_{1.973}=$ $23.70, \mathrm{p}<.001$. Restrained eaters (accurately) judged their current body size as larger than did unrestrained eaters. There was also a significant interaction between Restraint and Ad Type on current body size perception, $\underline{F}_{-2.97)}=4.22, \mathrm{Q}<.02$. Restrained eaters in the thin-body condition judged their current body size to be $\underline{\text { smaller }}(\underline{\mathrm{M}}=3.92 . \underline{\mathrm{SE}}=.30)$ than did those in the large-bodies condition $(\underline{\mathrm{M}}=4.80, \underline{\mathrm{SE}}=.34)(\underline{\mathrm{t}} 92)=1.99, \mathrm{~g}<.05)$ and marginally smaller than did those in the control ad condition $(\underline{\mathrm{M}}=4.53, \underline{\mathrm{SE}}=.29)$ 
$\left(\mathrm{t}_{92)}=1.61, \mathrm{~g}<.15\right)$. On the other hand. unrestrained eaters in the thin-body condition judged their current body size as marginally larger $(\underline{M}=3.83, \underline{S E}=.19)$ than did those in the control ad condition $(\underline{M}=3.21, \underline{\mathrm{SE}}=.18), \mathrm{t}_{92)}=1.75, \underline{\mathrm{p}}<.10$. The 2-way (Restraint by Ad Type) ANOVA on ideal body size also revealed a significant interaction. $\underline{E}_{(2.97)}=$ 3.29. $\mathrm{p}<.05$. Restrained eaters in the thin-body condition rated their ideal body size as smaller $(\underline{\mathrm{M}}=2.65 . \underline{\mathrm{SE}}=.15)$ than did those in either the large-body $(\underline{\mathrm{M}}=3.30 . \underline{\mathrm{SE}}=.21)$ or product-only condition $(\underline{\mathrm{M}}=3.37, \underline{\mathrm{SE}}=.19), \underline{\underline{\mathrm{t}}} \mathrm{S}_{(92)}>2.42, \mathrm{p}<.05$. Unrestrained eaters rated their ideal body size as the same across conditions. Means and standard errors for ideal and current body size perception across restraint and exposure conditions are shown in Table 1.

Similarity Ratings. Given the body-image self-enhancement effects exhibited by restrained eaters who viewed the thin body images, we hypothesized that these participants may also feel more similar to the models featured in the magazine advertisement. While mainly included to boost our cover story to participants. the "Consumer Response Questionnaire" allowed us to examine the question of how similar participants felt to the models. A 2-way ANOVA performed on similarity ratings tor participants in both the thin- and large-body ad conditions revealed a significant main effect of restraint, $\underline{E}_{(1.51)}=4.24, \underline{p}<.05$; in general, restrained eaters felt more similar to the models than did unrestrained eaters. This main effect was qualified by a significant interaction between restraint and ad type, $E_{(1.31)}=5.24 . \mathrm{g}<.03$. Restrained eaters felt more similar to the large models $(\underline{M}=4.11, \underline{\mathrm{SE}}=.39)$ than they did to the thin models $(\underline{\mathrm{M}}$ $=2.88, \underline{\mathrm{SE}}=.39)\left(\mathrm{t}_{4 \lambda}=2.28, \mathrm{p}<.05\right)$, whereas unrestrained eaters felt similar to large 
$(\underline{M}=2.50 . \underline{\mathrm{SE}}=.3 \mathrm{l})$ and thin $(\underline{\mathrm{M}}=2.91, \underline{\mathrm{SE}}=.33)$ models equally. Restrained eaters did not differ from unrestrained eaters in how similar they felt to the thin models. only in how similar they felt to the large models, $\mathrm{t}_{47}=3.10, \mathrm{p}<.01$.

We realized that our results would be even more compelling if we could demonstrate that trait body dissatisfaction did not better explain the observed interactions. Accordingly, we reanalyzed the key results (intake, ideal body size, current body size. appearance self-esteem) using a median split on trait body dissatisfaction (a subscale of the Eating Disorder Inventory, Garner et al., 1983). given after the Restraint Scale at the end of the study. The interactions between ad type and body dissatisfaction were not significant with respect to intake, ideal body size, current body size, or appearance selfesteem. That is, restraint, and not body dissatisfaction, was the key individual difference variable in moderating responses to media-portrayed idealized body images.

\section{Discussion}

The results of Study 1 replicated the finding of previous researchers that restrained eaters engage in disinhibited eating after being shown media-portrayed thin. idealized body images. As was predicted on the basis of the findings of Strauss et al. (1994) and Seddon and Berry (1996), restrained eaters who viewed idealized body images in magazine ads ate significantly more than did those who viewed ads featuring either plussize models or product-only ads. Negative affect or other evidence of ego threat, as had been predicted by Strauss et al. (1994), however. did not mediate this effect. Exposure to idealized body images did not make restrained eaters feel worse about themselves in terms of body image, mood, or self-esteem. Instead, restrained eaters, but not 
unrestrained eaters, reported a thinner ideal body size, and a thinner current body size following exposure to idealized body images. Restraint, and not trait body dissatisfaction. was the key individual difference variable in explaining the observed interactions. Restrained eaters also demonstrated a trend toward increased appearance self-esteem after viewing the thin body ads, as had participants in the study by Mills (1996). Despite being objectively heavier than were unrestrained eaters. restrained eaters felt as similar to the thin models as did their objectively thinner unrestrained counterparts. In other words, restrained eaters self-enhanced following exposure to idealized body images. After looking at very thin models, chronic dieters report not only that they want to be thinner, but that they are in fact thinner. It seems that. for the moment. restrained eaters motivation to inhibit eating was decreased.

This counterintuitive shift in self-evaluation resulting from exposure to idealized body images suggests a more complex role of the mass media in disordered eating than was originally proposed by the sociocultural model of eating disorders. Not all women feel worse after viewing pictures of ultra-thin models in the media. In the present study. dieters appear to have envisioned themselves as being thinner than usual after looking at idealized body images, reflecting an enhanced, not worsened, conception of their bodies. On the other hand, dieters did not feel better in general or report more positive affect. After finding evidence of counterintuitive self-enhancement following media exposure. Myers and Biocca (1992) suggested the possibility of a thinness fantasy induced by media exposure. Instead of feeling worse about herself upon seeing slim media images, a dieter may engage in a fantasy of believing herself to be thin and experience a temporary feeling 
of thinness. The consequence of such a shift in self-perception may be the removal of inhibition and dietary restraint, as evidenced by restrained eaters' disinhibited eating. Precisely why dieters overate following exposure to the idealized body images is still uncertain. but it is plausible that feeling thinner made dieters less concerned with restricting their food intake.

\section{Study 2}

Dietary restraint status moderates the effects of media exposure. with dieters showing evidence of self-enhancement following exposure to idealized body images in Study 1 . Dieters may be more likely than non-dieters to self-enhance after viewing thin models because weight and shape are personally relevant to them and they have undertaken dieting as a means of achieving a thinner physique. Dieters probably also have thinness-attainability beliefs that set them apart from unrestrained eaters. If they didn't see thinness as achievable, they presumably wouldn't be dieting. Thus, seeing pictures of thin models may strengthen dieters' hopes that they, too. will soon be thin and attractive. Study 2 investigated the role of thinness-attainability beliefs in heightening or diminishing the self-enhancement effect in restrained eaters. It was predicted that strengthening a dieter's belief that thinness is attainable would heighten self-enhancement resulting from exposure to idealized body images. On the other hand. weakening a dieter's belief that thinness is achievable should extinguish self-enhancement and may even elicit a negative contrast effect following exposure to ideal body images. 


\section{Method}

\section{Participants}

Sixty-one female restrained eaters between the ages of 18 and $25(\underline{M}=19.56 . \underline{S E}$ $=.16)$ enrolled in Introductory Psychology at the University of Toronto at Mississauga volunteered to participate. All participants scored 15 or higher on the Restraint Scale. Students participated in the study to partially satisfy course requirements or they were paid \$7.00. APA ethical principles (American Psychological Association. 1992) were applied to all participants. Height and weight were collected from participants in order to calculate BMI. A one-way ANOVA revealed no significant differences between experimental conditions with respect to BMI.

\section{Materials}

Magazine Advertisements. The thin-body ads and product-only ads used in the previous two studies were again used as the ad-type manipulation.

Thinness-attainability articles. Three one-page articles were written for the present study. The high-attainability article, entitled "New Hope for the Slimward Bound," described how diets can and often do work. and encouraged the reader not to give up trying to lose weight (high thinness-attainability condition). The low-attainability article, entitled "Fat Chance: The truth about dieting," described how the vast majority of diets fail and encouraged the reader to give up trying to alter a genetically determined physique (low thinness-attainability condition). A neutral thinness-attainability article. entitled "Sheep in Wolves' Clothing," described how wolves are misunderstood as a species and are actually very shy and docile (neutral thinness-attainability condition). 


\section{Measures}

Dietary Restraint. The Restraint Scale (Polivy et al.. 1988) was again used to measure dietary restraint status.

Negative Affect. The Affect Rating Scale (ARS; Atkinson \& Polivy, 1976) was again used to measure depression, anxiety, hostility, and total negative affect.

Appearance State Self-Esteem. The Current Thoughts Scale (Heatherton \& Polivy, 1991) was again used to measure state appearance self-esteem.

Current and Ideal Body-Size Perception. The present study again used the index adapted from Fallon and Rozin's (1985) measure of body perception in order to measure current and ideal body-size perception.

\section{Procedure}

The experiment was presented to participants as a market-research study entitled "The Effectiveness of Advertising." Upon debriefing at the end of the study, no participant revealed knowledge of the true purpose of the study. A single experimenter tested each participant in one-hour sessions between 11:00 a.m. and 6:00 p.m. Participants were seated alone at a table in a private room. After reading and signing a consent form and completing initial mood and hunger ratings, each participant was presented with a one-page article to read. Participants were randomly assigned to one of three conditions, reading either the high, low, or neutral thinness-attainability article. Participants were told that we were interested in knowing what they thought of these articles and that they were the types of articles that might appear in a magazine. Participants were then given magazine ads, featuring either products only or thin body 
images. or "Consumer Response Questionnaires" as in the previous studies, and were then given the state measures used in the previous studies. ${ }^{5}$ Thus, the procedure in Study I was repeated, including only the thin-body and product-ad conditions. with the addition of the attainability article before media exposure.

\section{Results}

On the basis of the findings of Study I and the predictions of Study 2, a series of planned comparisons within the between-subject factors of ad type and thinness attainability were analyzed. Within the high-attainability conditions, means from the thin-body ads were compared to those from the product ads in order to test whether selfenhancement was increased when thinness was perceived as attainable. Within the thin-ads conditions. means from the high-attainability condition were compared to those from the low-attainability condition to test whether self-enhancement was affected by attainability beliefs. Finally, within the attainability control conditions, means from the thin-ads condition were compared to those from the product-ads condition in order to test whether restrained eaters self-enhance under neutral conditions. Means and standard errors for negative affect, state self-esteem, and current and ideal body-size perception are shown in Table 2.

Insert Table 2 about here

${ }^{5}$ Participants were also given a taste test following the state measures and before the personality measures. However, eating across restrained eaters in all conditions was minimal and no significant main effects nor interactions were found. 
Negative Affect. It was hypothesized that while, under normal conditions and as was found in Study 1, participants in the thin-ads condition would be no less anxious than those in the product-ads condition. strengthening thinness-attainability beliefs may heighten the self-enhancement effect, thus bringing about mood (i.e., anxiety, depression. hostility) changes. Maximum scores are 76 for anxiety, 76 for depression. and 80 for hostility.

Within the high-attainability conditions, participants who viewed the thin-body ads were marginally less anxious $(\underline{M}=27.4 . \underline{S E}=2.67)$ than were those who viewed the product ads $(\underline{\mathrm{M}}=34.00, \underline{\mathrm{SE}}=2.67), \mathrm{t}_{55}=1.79 . \mathrm{Q}<.10$. In terms of depression scores. within the high-attainability conditions, participants who viewed the thin ads were less depressed $(\underline{\mathrm{M}}=25.90, \underline{\mathrm{SE}}=2.26)$ than were those who viewed the product ads $(\underline{\mathrm{M}}=$

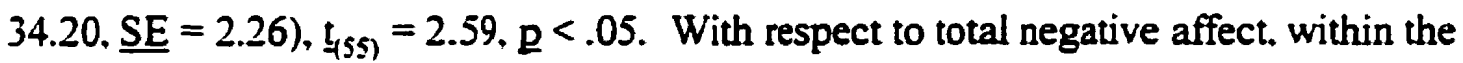
high-attainability conditions those who viewed the thin ads were less upset $(\underline{M}=86.60$. $\underline{S E}=6.82)$ than were those who viewed the product ads $(\underline{\mathrm{M}}=106.10, \underline{\mathrm{SE}}=6.82) . \underline{t_{551}}=$ $2.03, \mathrm{p}<.05$.

Within the thin-body ad conditions, participants who read the high-attainability article were less anxious $(\underline{M}=27.40, \underline{\mathrm{SE}}=2.67)$ than were those who read the lowattainability article $(\underline{\mathrm{M}}=35.90, \underline{\mathrm{SE}}=2.67), \underline{\mathrm{t}}_{557}=2.25 . \mathrm{g}<.05$. Within the thin-ad conditions those who read the high thinness-attainability article were marginally less upset $(\underline{M}=86.60, \underline{S E}=6.82)$ than were those who read the low thinness attainability article $(\underline{M}=103.70, \underline{S E}=6.82), t_{55}=1.78, \underline{\underline{Q}}<.10$. No other planned comparisons reached significance. 
Appearance State Self-Esteem. It was hypothesized that participants who viewed the thin bodies would have higher appearance self-esteem than those who viewed the product ads, and that the effect would be more pronounced in the high thinness-attainability condition. Within the high thinness-attainability conditions. those participants who viewed the thin-body ads had marginally higher appearance self-esteem $(\underline{M}=19.10, \underline{S E}=1.25)$ than did those who viewed the product ads $(\underline{M}=15.80 . \underline{S E}=$ $1.25), \mathrm{t}_{(55)}=1.88, \mathrm{p}<.10$. No other planned comparisons involving appearance selfesteem were significant.

Current and Ideal Body-Size Perception. Within the neutral attainability conditions. participants who viewed the thin ads had smaller current body-size estimates $(\underline{M}=3.36, \underline{S E}=.29)$ than did those who viewed the product ads $(\underline{M}=4.15 . \underline{S E}=.31)$. $t_{(55)}=2.00 . \mathrm{g}<.05$. No other planned comparisons involving current body-size perception were significant. No planned comparisons were significant for ideal body size.

\section{Discussion}

Within the neutral-attainability condition, we expected to replicate the findings of Study 1 and find evidence of self-enhancement following exposure to thin ads for restrained eaters. As predicted, participants who viewed the idealized body-image ads felt thinner than did those who viewed the product-only ads. Thus, as in Study I. looking at thin idealized bodies made dieters report that they, too, are currently thin. Also as in Study 1 , there were no positive mood effects (i.e.. depression. anxiety. hostility) resulting from simply viewing idealized body images and under conditions of neutral thinness 
attainability. Without manipulating thinness-attainability beliefs, the effect of exposure to thin media images appears to be limited to enhanced self-perception rather than emotion.

When we examined dieters' response to viewing thin ads under conditions of either enhanced or diminished thinness-attainability beliefs, we did find evidence of mood and state self-esteem effects. Participants who viewed the thin-body ads after reading that thinness is achievable through diet and exercise felt less anxious and better about their bodies than did those who had read that thinness is determined genetically. This finding makes sense in the context of the inspiration explanation for selfenhancement following exposure to idealized body images. Making dieters believe that their diets do in fact work sets the stage for hopefulness that they too can be thin like the models shown in the magazine advertisements; that hopefuiness, in turn. extends beyond self-perception and impinges on their sense of well-being.

\section{Study 3}

Study 3 was aimed at examining whether exposure to media-portrayed idealized body images enhances motivation as well as self-perception in restrained eaters. Studies 1 and 2 suggested that restrained eaters self-enhance following exposure to thin media images. Presumably, this self-enhancement effect following exposure to a highly attractive target is mediated by inspiration, as has been proposed by previous researchers (e.g., Collins, 1996; Lockwood \& Kunda. 1997). Because weight and shape are personally relevant for them and because they are in the process of attempting to lose weight, restrained eaters may well feel inspired by images of thin bodies that they see in 
magazines. This hypothesized inspiration effect makes salient for them a thinner possible self that is incorporated into their current self-image. If it were true that restrained eaters feel inspired after viewing thin media images, they should also be expected to demonstrate other evidence of inspiration. In Study 3 and in accordance with the hypothesized inspiration explanation for self-enhancement found in Studies 1 and 2. exposure to idealized media images was predicted to produce enhanced motivation to diet, higher expectations of weight loss, and more extreme commitment to increased effort to achieve thinness among restrained eaters.

Despite the finding that restrained eaters exhibited disinhibition in Study 1 following exposure to thin media images, this eating effect does not rule out the inspiration explanation for self-enhancement. Restrained eaters reported feeling thinner after looking at thin media images than after looking at neutral images. making them. at that moment. less concerned with restricting their intake. However. inspiration through increased awareness of a future thinner self is predicted to serve as a goal for future eating behaviour and make restrained eaters more likely to want to lose weight. In Study 3, the degree to which restrained eaters would want to attempt to restrict their future intake following exposure to thin media images was measured in order to test this hypothesis. If, as concluded from Studies 1 and 2, restrained eaters feel inspired by thin media images, we would expect them to report that they are more likely to want to attempt to lose weight. as well as more hopeful that they can lose weight.

If the predictions of Study 3 are correct and exposure to idealized body images in the media makes restrained eaters more motivated to lose weight, then, in the long run, 
exposure to media images may contribute to dieting behaviour. A second and related purpose of Study 3 was to examine the ability of other factors in enhancing motivation to diet. We chose to examine the role of receiving negative weight-related information in making restrained eaters want to lose weight. McFarlane et al. (1998) have previously shown that giving restrained eaters negative false feedback about their weight makes them feel depressed. anxious, and worse about their appearance. However. these authors did not look at motivation to diet following a weight-related threat. One of the original purposes of the present set of studies was to examine whether exposure to mediaportrayed idealized body images significantly contributes to dieting behaviour in young women. Therefore. Study 3 sought to demonstrate that exposure to media images contributes to motivation to lose weight more than do other relevant factors (e.g.. perceiving oneself as having gained weight). For this purpose, Study $j$ aiso concurrentiy measured the effects of receiving negative weight-related information on self-perception and motivation to lose weight. As a further test of the effect of media-exposure on motivation to lose weight, a weight-related threat condition (i.e., orally guessing an individual's weight to be 15 pounds higher than her true weight) was included as a comparison to the media-exposure condition. It was predicted that exposure to mediaportrayed body images would result in more reported motivation to lose weight than would receiving negative weight-related feedback. 


\section{Method}

\section{Overview of the Method}

Restrained and unrestrained eaters were randomly assigned to one of four conditions. In two of the conditions, participants were exposed to magazine ads featuring either 1) thin media images, or 2) products only. In the other two conditions, participants either received 1) threatening weight-related information, or 2) no information about their weight.

\section{Participants}

Eighty-nine females between the ages of 18 and $25(\underline{M}=19.52 . \underline{S E}=.14)$ enrolled in Introductory Psychology at the University of Toronto at Mississauga volunteered to participate. Participants were recruited from another unrelated psychology experiment in the department. ${ }^{6}$ Students participated in the study either to partiaily satisfy course requirements or they were paid \$7.00. APA ethical principles (American Psychological Association. 1992) were applied to all participants, including institutional approval. informed consent, not offering undue inducement for research participants, no unnecessary deception, informed sharing and utilizing of data. and providing participants with information about the study. Objective height and weight were collected from participants at the end of the study in order to calculate their BMI. A one-way ANOVA revealed no significant differences between experimental conditions with respect to BMI.

\footnotetext{
${ }^{6}$ This was done so that, for the weight-threat condition, the experimenter knew participants' weights before the present study and could thereby manipulate the weight guessed for a participant.
} 


\section{Materials}

Magazine Advertisements. The thin-body ads and product-only ads used in the previous two studies were again used in order to manipulate the ad type to which participants were exposed.

Sample Meal Plans. One-page laminated sample meal plans presented food types and quantities suggested for an individual's daily intake (i.e., breakfast. lunch, dinner. and snacks). These diet plans were made up for the purposes of the study. The "lenient" diet also contained the following information written at the top of the page: "-This diet consists of 1600 calories per day, a reduction of 600 calories per day from what the average woman eats. This program is designed to produce a weight loss of one-half to one pound every two weeks." The "moderate" diet stated that it "consisted of 1200 calories per day, a reduction of 1000 calories per day from what the average woman eats. and was designed to produce a weight loss of one to two pounds per week." The "strict" diet stated that it "consisted of 800 calories per day, a reduction of 1400 calories per day from what the average woman eats, and was designed to produce a weight loss of three to five pounds per week."

\section{Measures}

Initial Mood. A 10-point visual-analog scale with 15 positive-negative adjective pairs (e.g., relaxed-anxious) was used to assess initial mood state before the experimental manipulation occurred in order to rule out pre-existing differences in mood between experimental conditions. 
Negative Affect. The Affect Rating Scale (ARS; Atkinson \& Polivy, 1976) was again used to measure depression, anxiety, hostility, and total negative affect.

State Self-Esteem. The Current Thoughts Scale (Heatherton \& Polivy. 1991) was again used to measure state self-esteem (appearance, social. performance. and total).

Current and Ideal Body-Size Perception. The present study again used the index adapted from Fallon and Rozin's (1985) measure of body perception in order to measure current and ideal body-size perception.

Dietary Restraint. The Restraint Scale (Polivy et al., 1988) was again used to measure dietary restraint status. As before, participants scoring 15 or higher were classified as restrained eaters (Polivy et al., 1988). Those participants scoring 14 or less were classified as unrestrained eaters.

Motivation to lose weight. In order to measure participants motivation for weight loss. additional items were added in a second page to the restraint questionnaire. Participants reported how many pounds they would like to lose over the next month (on a 5-point Likert scale; $0-4,5-9,10-14,15-19$, or $20+)$, how many pounds they thought they would realistically lose over the next month (5-point Likert scale; 1-4, 5-9, 10-14, 15-19. or $20+$ ), how likely it was that they will diet over the next week (4-point Likert scale: "not at all", "slightly", "moderately", or "very much"), and the most stringent amount of food restriction (10-point Likert scale; "mild" to "extreme" restriction) and exercise (10-point Likert scale; "mild" to "extreme" exercise) they would be willing to attempt on a daily basis, if they could be reasonably sure that their program would result in successful weight loss. 


\section{Procedure}

The experiment was again presented to participants as a market-research study entitled "The Effectiveness of Advertising." Upon debriefing at the end of the study, no participant revealed knowledge of the true purpose of the study. Each participant was tested in a one-hour session between 11:00 a.m. and 6:00 p.m.. Upon arrival at the lab. participants were seated alone at a table in a private room, signed a consent form. and completed a visual-analog scale measuring initial mood. A one-way ANOVA revealed no differences between experimental conditions with respect to initial mood.

Participants were randomly assigned to one of four experimental conditions. In two of the conditions, participants were presented with 12 laminated full-page colour advertisements featuring either thin bodies or products only. The same ads used in Studies 1 and 2 were used in Study 3. Participants in the thin-ads condition viewed seven ads showing thin and attractive female models' bodies plus five control ads featuring products and no human figures. Participants in the neutral-ads condition viewed 12 product-only ads. Participants in both ad conditions were given a "Consumer Response Questionnaire" to complete for each ad and were told that they had 10 minutes to look at and rate the ads. After 10 minutes, the experimenter returned to collect the ads and completed market-research questionnaires. All participants tinished looking at and rating the ads in the allotted time.

In the other two experimental conditions, participants were told that the market research portion of the experiment would come later and betore then the experimenter needed to collect some personal information from them. Participants were asked a series 
of questions orally by the experimenter. Participants in the weight-related threat condition were asked their age and height. Then the experimenter orally guessed the participant's weight and asked for confirmation (i.e.. "['d guess that you weigh pounds. Is that right?"). Prior to the experiment. the experimenter already knew the participant's objective weight from a different psychology experiment from which the present study's participants were recruited. In order to manipulate the amount of threatening weight-related information the participant received, the experimenter orally guessed the participant's true weight plus 15 pounds. The mean length of time between the collection of the participant's objective weight from the other study and her participation in the present study was two weeks. While it is possible that a participant's weight might have changed during that time, any differences were assumed to be small and equivalent across experimental conditions. Participants in the no-threat condition were just asked their age, height, and weight orally by the experimenter.

Participants in all four conditions were then administered self-report measures assessing negative affect, state self-esteem, and current and ideal body-size perception. The same measures used in Studies I and 2 were used in Study 3. For participants in the thin-ads and product-ads conditions, the experimenter explained that these state measures were for another researcher collecting data for a separate study. This step was taken to minimize any demand characteristics present for participants in either of the ad-exposure conditions (again, as in Studies $l$ and 2). After participants rang a bell to indicate that they had finished completing the self-report measures. the experimenter returned and gave the following oral instructions: 
The company that has asked us to gather the market research data for them is offering participants in my study free enrollment in one of three diet plans they have developed. If you would like to participate, I will give you a package to take home containing sample meal plans for a 6-week period, which you can use at your own discretion. You do not have to return to the lab in the meantime or report back to us. Participation in this is totally voluntary. and you can choose to enroll in any one diet or decline to enroll without penalty. I'll leave you alone for a few minutes to peruse the examples on your own. Just ring the bell when you're done.

The participant was then presented with the three full-page. laminated sample meal plans described in the Materials section (i.e., "lenient," "moderate," and "strict”). The experimenter returned when the participant rang the bell and her decision whether to participate in a diet plan was recorded. Participants in all four conditions were then administered the restraint scale. Finally, all participants were thoroughly debriefed and probed as to what they saw to be the purpose of the experiment. For participants in the weight-related threat and no-threat conditions, the debriefing began with the explanation that there was, in fact, no market-research component to the experiment.

\section{Results}

Study 3 consisted of two $2 \times 2$ between-subjects designs (Restraint $\times$ Ad type. and Restraint $\times$ Weight-related Information). The main hypotheses regarding 1) the effects of viewing thin media images on restrained and unrestrained eaters. and 2) the effects of receiving threatening weight-related information on restrained and unrestrained eaters were tested. ANOVAs were performed with the above variables as independent variables and negative affect, state self-esteem, current and ideal body-size perception, desire to 
participate in a weight-loss program, and motivation to diet as the dependent variables of interest.

The Effects of Viewing Thin Media Images on Restrained and Unrestrained Eaters

The first hypothesis was that viewing advertisements containing thin media images would result in improved body-image parameters for restrained, but not unrestrained, eaters as compared to viewing product-only images. We further predicted that, should inspiration mediate self-enhancement among dieters following exposure to thin media images, they should be more willing to attempt to diet, be more hopeful about future weight loss, and expect to lose more weight.

Initial Mood. A one-way ANOVA revealed that, despite random assignment to experimental condition, participants in the thin ads condition had a lower initial mood $(\underline{\mathrm{M}}$ $=48.40 . \underline{\mathrm{SE}}=1.32)$ than did those in the product-only ads condition $(\underline{\mathrm{MI}}=51.96 . \underline{\mathrm{SE}}=$ 1.14), $\underline{E}_{(1.40)}=4.00, \underline{p}^{<.05}$. Accordingly, initial mood was entered as a covariate into all ensuing analyses.

Negative Affect. Initial mood as a covariate had an effect on participants' anxiety $\left(\underline{E}_{11,+01}=6.43, \mathrm{~g}<.02\right)$ and depression $\left(\underline{E}_{(1.40)}=9.71 . \mathrm{g}<.01\right)$ scores. There were no significant main effects (nor an interaction effect) for ad type or restraint status on anxiety, depression, or hostility scores.

State Self-Esteem. There was a main effect of restraint status on appearance selfesteem $\left(\underline{E}_{(1.40)}=18.89, \mathrm{Q}<.001\right)$ and social self-esteem $\left(\underline{E}_{(1,40)}=8.52, \mathrm{p}<.01\right)$, with restrained eaters scoring lower on both measures $\underline{\underline{M}}=16.41, \underline{\mathrm{SE}}=1.21 ; \underline{\mathrm{M}}=24.27 . \underline{\mathrm{SE}}=$ 1.19 , respectively) than did unrestrained eaters $(\underline{\mathrm{M}}=22.78, \underline{\mathrm{SE}}=.79 ; \underline{\mathrm{M}}=28.26 . \underline{\mathrm{SE}}=$ 
.79). Restrained eaters scored marginally lower on performance self-esteem $(\underline{M}=25.73$, $\underline{S E}=1.07)$ than did unrestrained eaters $(\underline{M}=28.09, \underline{S E}=.78), \underline{F}_{(1.40)}=3.45, \underline{\mathrm{Q}}<.07$. There were no significant main effects of ad type or interactions between ad type and restraint status on appearance, social, or performance state self-esteem.

Current and Ideal Body-Size Perception. Restrained eaters rated their current body size $(\underline{M}=4.50, \underline{S E}=.25)\left(\underline{F}_{(1 .+0)}=13.06, \underline{p}<.001\right)$ and the difference between their current and ideal body sizes $(\underline{\mathrm{M}}=1.64 . \underline{\mathrm{SE}}=.89)\left(\underline{\mathrm{E}}_{1 / .+0)}=27.84 . \mathrm{Q}<.001\right)$ as larger than did unrestrained eaters $(\underline{\mathrm{M}}=3.43, \underline{\mathrm{SE}}=.15 ; \underline{\mathrm{M}}=.41 . \underline{\mathrm{SE}}=.65$, respectively). There was no main effect of restraint on ideal body size. Ad type had no effect. alone or in interaction with restraint. on current, ideal, or the difference between current and ideal body sizes.

Desire to Participate in Weight-Loss Program. The frequencies of participants requesting to participate in any of the weight loss programs, as well as a breakdown of which program they preferred to try are presented in Table 3. A chi-square analysis revealed no significant differences in the frequencies between cells as a function of restraint or ad type.

Insert Table 3 about here

Weight-Loss Motivation. Restrained eaters hoped to lose more weight over the next month $\underline{\mathrm{M}}=2.41, \underline{\mathrm{SE}}=.21)(\underline{\mathrm{F}}(1,40)=7.49, \underline{\mathrm{p}}<.01)$, were more likely to diet over the next week $(\underline{M}=2.59, \underline{\underline{S E}}=.20)(\underline{F}(1,40)=14.46, \underline{\mathrm{p}}<.001)$, and were willing to 
commit to more extreme restriction $(\underline{\mathrm{M}}=5.77, \underline{\mathrm{SE}}=.40)(\underline{\mathrm{E}}(1,40)=4.40, \mathrm{~g}<.05)$ than were unrestrained eaters $(\underline{M}=1.61, \underline{\mathrm{SE}}=.19 ; \underline{\mathrm{M}}=1.61, \underline{\mathrm{SE}}=.15 ; \underline{\mathrm{M}}=4.61, \underline{\mathrm{SE}}=.37$. respectively). They did not, however, expect to lose any more weight than their unrestrained counterparts. There were no effects of ad type on these dependent variables. The Effects of Receiving Negative Weight-Related Information on Restrained and Unrestrained Eaters

It was hypothesized that receiving threatening weight-related information would affect body-image parameters for restrained, but not unrestrained, eaters as compared to not hearing threatening weight-related information.

Initial Mood. There was no difference between experimental conditions with respect to initial mood.

Negative Affect. As was found across the ad conditions, restrained eaters had marginally higher anxiety scores $(\underline{\mathrm{M}}=35.95 . \underline{\mathrm{SE}}=1.28)$ than did unrestrained eaters $(\underline{\mathrm{M}}$ $=31.04, \underline{\mathrm{SE}}=1.56)\left(\underline{\mathrm{E}}_{(1 .+0)}=3.74, \underline{\mathrm{p}}<.07\right)$ across the weight-related information conditions. There was a marginal main effect of weight-related threat on hostility $\left(\underline{F}_{(1.40)}\right.$ $=\mathrm{Q}<.12)$, such that participants who received threatening weight-related information felt more hostile $(\underline{M}=35.09, \underline{\mathrm{SE}}=1.51)$ than did those who did not $(\underline{\mathrm{M}}=32.05 . \underline{\mathrm{SE}}=1.04)$.

State Self-Esteem. Restrained eaters had lower appearance self-esteem $(\underline{\mathrm{M}}=$ 17.42. $\underline{\mathrm{SE}}=1.10)\left(\underline{E}_{(1 .+0)}=6.32, \underline{\mathrm{p}}<.02\right)$ and marginally lower social self-esteem $(\underline{\mathrm{M}}=$ $24.79, \underline{\mathrm{SE}}=1.45)\left(\underline{\mathrm{E}}_{(1 .+0)}=3.29, \mathrm{p}<.08\right)$ than did unrestrained eaters $(\underline{\mathrm{M}}=21.25 . \underline{\mathrm{SE}}=$ $1.01 ; \underline{\mathrm{M}}=28.08, \underline{\mathrm{SE}}=1.06$ respectively). There was a trend towards an interaction between threat condition and restraint on appearance self-esteem. $\underline{E}_{(1 .+0)}=1.74, \mathrm{~g}<.20$. 
Restrained eaters had marginally higher appearance self-esteem in the threat condition ( $\underline{\mathrm{M}}$ $=19.22 . \underline{\mathrm{SE}}=1.46)$ than in the no-threat condition $(\underline{\mathrm{M}}=15.80 . \underline{\mathrm{SE}}=1.50) . \mathrm{t}_{+01}=1.63 . \mathrm{D}$ $<.10$.

Current and Ideal Body-Size Perception. Restrained eaters rated their current body size as larger $(\underline{M}=4.75 . \underline{\mathrm{SE}}=.33)$ than did unrestrained eaters $(\underline{\mathrm{M}}=3.54 . \underline{\mathrm{SE}}=$ $.22), \mathrm{E}_{(1,+0)}=11.51, \mathrm{~g}<.01$. In addition, participants in the weight-related threat condition rated their current body size as smaller $(\underline{M}=3.70, \underline{S E}=.22)$ than did those in the no-threat condition $(\underline{M}=4.48 . \underline{S E}=.34), \underline{\mathrm{F}}_{(1.40)}=5.58, \mathrm{p}<.03$. However, both of these main effects were qualified by an interaction between threat condition and restraint. $\underline{E}_{(1.40)}=4.53, \mathrm{p}<.04$. Restrained eaters in the threat condition rated their current body size as significantly thinner $(\underline{\mathrm{M}}=3.95, \underline{\mathrm{SE}}=.31)$ than did those in the no-threat condition $(\underline{M}=5.55, \underline{S E}=.47), \mathrm{t}_{(40)}=3.08, \underline{\mathrm{p}}<.01$. There was also a marginal interaction between restraint and threat condition on ideal body size, $\underline{E}_{(1,40)}=3.77, \mathrm{Q}<.06$. Restrained eaters in the threat condition rated their ideal body size as significantly thinner $(\underline{\mathrm{M}}=2.70 . \underline{\mathrm{SE}}=$ .11) than did those in the no-threat condition $(\underline{\mathrm{M}}=3.50, \underline{\mathrm{SE}}=.39), \mathrm{t}_{(+0)}=2.42, \mathrm{p}<.05$. Threat condition had a marginal effect on the difference between current and ideal body sizes, $\underline{E}_{(1.40)}=3.56, \underline{Q}<.07$. Participants in the threat condition rated their current and ideal bodies as closer in size $(\underline{\mathrm{M}}=.82, \underline{\mathrm{SE}}=.19)$ than did those in the no-threat condition $(\underline{M}=1.27, \underline{\mathrm{SE}}=24)$. The means for appearance state self-esteem, current, and ideal body-size perceptions are shown in Table 4. 
Insert Table 4 about here

Desire to Participate in Weight-Loss Program. The frequencies of participants requesting to participate in any of the weight loss programs. as vell as a breakdown of which program they preferred to try are presented in Table 5. Among restrained eaters in the weight-related threat condition, a higher proportion agreeing to participate in a diet program selected the moderate diet as compared to restrained eaters in the no-threat condition. $\underline{X}_{(2)}^{2}=8.83, \underline{p}<.02$.

Insert Table 5 about here

Weight Loss Motivation. Restrained eaters hoped for more weight loss over the next month $(\underline{M}=2.75, \underline{S E}=.29)\left(\underline{F}_{1.40)}=9.53, \underline{\mathrm{p}}<.01\right)$, were more likely to diet over the next week $(\underline{M}=2.55, \underline{\mathrm{SE}}=.21)\left(\underline{E}_{(\mathrm{t}, 40)}=23.68, \mathrm{p}<.001\right)$, were willing commit to more extreme restriction $\left.(\underline{M}=6.10, \underline{\mathrm{SE}}=.47) \underline{\mathrm{E}}_{(L+40)}=7.05, \underline{\mathrm{p}}<.02\right)$, and more extreme exercise $(\underline{M}=6.40, \underline{S E}=.41)\left(E_{(1,+0)}=4.74, \underline{p}<.04\right)$ than were unrestrained eaters on the same measures $\underline{\underline{M}}=1.75, \underline{\mathrm{SE}}=.16 ; \underline{\mathrm{M}}=1.42, \underline{\mathrm{SE}}=. \mathrm{I} ; \underline{\underline{\mathrm{M}}}=4.46 . \underline{\mathrm{SE}}=.40 ; \underline{\mathrm{M}}=5.20$. $\underline{\mathrm{SE}}=.35$, respectively).

\section{Discussion}

Study 3 attempted to show that looking at thin media images increases motivation to diet, in line with the inspiration explanation of the "thin fantasy" demonstrated by 
restrained eaters after viewing such images in Studies 1 and 2. Unfortunately, the lack of a finding of self-enhancement among restrained eaters who viewed the thin media images precluded a reasonable test of this hypothesis. It is not entirely clear at present why selfenhancement was not found in Study 3. Even without initial mood as a covariate, there was still no self-enhancement found. It is possible that mood, although not previously shown to be affected by inspiration, may set the stage for self-enhancement and that a generally positive mood may be a necessary precondition for inspiration to occur.

Study 3 also included a separate test of whether receiving negative weight-related information would affect motivation to diet. The findings showed that receiving negative weight-related information did not affect motivation to diet among restrained eaters. In terms of willingness to sign up for a weight loss program following a weight-related threat, the results were unclear. Contrary to our predictions, restrained eaters in the threat condition were more likely to choose the moderate over the lenient or strict diet programs. Restrained eaters in the no threat condition were actually more likely to choose the strict diet than either the lenient or moderate diet. Given the relatively small sample size, and the unexpectedness of the finding, future research with a larger sample may help to clarify this result.

The most intriguing and unexpected result from Study 3 was that selfenhancement occurred in response to receiving negative weight-related information from another person. When the experimenter guessed restrained eaters' weight as 15 lbs. heavier than their true weight, they subsequently rated their ideal body size, current body size, and the discrepancy between their current and ideal body sizes as marginally 
smaller. At first, these results appear to stand in direct contrast to those of McFarlane. Polivy, and Herman (1998). These authors found that when dieters were weighed 5lbs. more than their true weight they felt more dissatisfied with their appearance. depressed. and anxious. A clue to explaining these discrepant findings may lie in the source of the negative weight-related feedback. In McFarlane et al's (1998) study, participants saw their weight on a scale (previously rigged to weight them 5lbs. heavy). As such. they had no option but to agree with the scale and. in turn. feel bad about their weight. On the other hand, in Study 3 participants received the negative weight-related information from an individual that they had just met (i.e., the experimenter). Elevated hostility scores for those in the threat condition suggest that participants felt negatively about the experimenter after hearing her guess their weight as 15 lbs. over their true weight. In this situation, restrained eaters could discount the subjective information they had just heard about their weight and convince themseives that they are actually thin (and that the experimenter really had no idea how much they weighed). The results of Study 3 illustrate that self-enhancement can result when negative weight-related information is received from a source that can be discounted. Future research should investigate further whether the source of negative weight-related feedback determines whether deflation or self-enhancement occurs among dieters. It is predicted that objective negative weight feedback generally leads to self-deflation, whereas subjective/arguably incurrect negative weight feedback can lead to self-enhancement. 


\section{General Discussion}

The set of studies presented here provides important evidence toward the debate over whether exposure to media-portrayed idealized body images adversely affect women. Study 1 found evidence of self-enhancement among restrained eaters following exposure to thin-ideal bodies in magazine ads. While seemingly counterintuitive. selfenhancement following exposure to thin media images has been reported previously (Mills. 1996; Myers \& Biocca, 1992; Henderson-King \& Henderson-King, 1997). but has been largely ignored by researchers in this field. It appears that restrained eaters experience a "thin fantasy" from looking at very thin, idealized body images in popular media. A study by McCabe, McFarlane, Polivy and Olmsted (2001) recently reported that restrained eaters chronically underreport their weight, even more so than do unrestrained eaters. suggesting that restrained eaters are adept at convincing themselves that they are thinner than they actually are. The present findings demonstrate that exposure to idealized body images activates this tendency and facilitates a shift toward seeing themselves as thin.

Study 2 demonstrated that differences in thinness-attainability beliefs affect how participants react to media-portrayed idealized body images. Unlike restraint status however, this variable is malleable (at least among restrained eaters) and can be affected merely by reading a short article on whether body size is determined by diet and exercise or by genetics. The finding that high thinness-attainability beliefs heighten selfenhancement helps to explain why it is specifically restrained. but not unrestrained eaters. who demonstrate media-induced self-enhancement. Fashion models inspire dieters to be 
thinner, and exposure to such thin media images makes salient to dieters a thinner possible self. Our results fit well with Lockwood and Kunda's (1997) theory that "superstars" (or supermodels in this case) can have inspirational effects on individuals under specific conditions. These authors have shown that self-relevant superstars provoke self-enhancement and inspiration when their success seems attainable. but selfdeflation when it seems unattainable. Thus, according to their theory, individuals for whom thinness is a self-relevant characteristic and who perceive it to be attainable (i.e.. dieters) feel inspired by idealized body images and evaluate their own bodies more positively. Inspiration appears to be a viable explanation for why some women enjoy reading beauty and fashion magazines, and why many go out of their way to buy them.

The inspiration explanation for self-enhancement was directly tested in Study 3 by examining whether looking at pictures of thin fashion models makes females more likely to want to undertake dieting as a means of controlling their weight and shape. Because of the lack of a self-enhancement effect among restrained eaters following exposure to thin media images, the inspiration explanation and the effects of viewing thin media images on weight loss motivation could not be properly tested.

The finding of self-enhancement in response to negative weight-related feedback in Study 3 introduces the prospect of self-enhancement elicited by a defensive reaction to threatening information about the self. Some could argue that the "thin fantasy" that is demonstrated by restrained eaters in response to thin media images reflects defensiveness and not inspiration. At this point in time, however, the inspiration explanation for the "thin fantasy" seems intuitively stronger. To begin with. many dieters are known to often 
use images of slender bodies to motivate themselves to lose weight. Some dieters will even stick pictures of thin supermodels on their refrigerators to strengthen their resolve to lose weight (Collins, 1996). In a recent issue of People weekly magazine (Sporkin, 2001. May 14), actress Catherine Zeta-Jones admitted to tearing out pictures of models in magazines and sticking them on her mirror. The diet industry frequently uses images of thin women to advertise weight-loss programs, using thin models to sell hopes of a thinner (and therefore happier) self (Mills, McCabe, \& Polivy, 1999). Furthermore. restrained eaters see thinness as attainable through dieting (Heatherton \& Polivy. 1994) and weight and shape are personally relevant to them. The characteristics of personal relevance and perceived attainability have been previously shown by Lockwood and Kunda (1997) to facilitate inspirational reactions to superstars (or. in dieters" case. supermodels). The resuits of study 2 support this aspect of the inspiration explanation. Finally, and most importantly, a defensive explanation of self-enhancement in response to thin media images does not fit with reliable findings of a significant correlation between media use and eating disorder symptomatology, including dieting behaviour (e.g.. Stice et al., 1994; Tiggeman \& Pickering, 1996). Why would dieters expose themselves to high thin-ideal content media only to engage defensive reactions in response to such images? Inspiration, on the other hand, does explain why dieters continue to expose themselves to such media. When they no longer feel thin and realize that dieting is not the answer to thinness, they return to such media for weight-loss advice and inspiration. perpetuating the "spiral" of dieting and eating disorders (Heatherton \& Polivy. 1992; Tiggeman \& Pickering, 1996). 
In sum, it seems that for restrained eaters receiving subjective negative weightrelated information can lead to self-enhancement for purposes of self-esteem protection. At the same time, looking at thin media images elicits a completely different process (i.e.. inspiration) with the same result (i.e., feeling thinner). Whereas a weight-related threat is likely to be threatening to a restrained eater's self-esteem. inspiration involves the salience of the possibilities of a future self, rather than the shortcomings of the present self.

\section{Conclusions}

The prevailing view in the literature is that thin media images promote body dissatisfaction (and associated negative mood) in (all) young women. The present findings dispute this assumption. Moreover, the fact that many women apparently enjoy reading beauty and fashion magazines and choose to do so has not been previously addressed by researchers in this area and is certainly inconsistent with the idea that idealized body images make all women feel bad about themselves. Our results demonstrate that dieters in particular report feeling thinner and more attractive after looking at thin, attractive models. Exposure to media-portrayed idealized body images appears to allow dieters to report that they see themsetves with a body more in line with their ideal. It is speculated here that this assimilation between ideal and current body size is due to inspiration from thin media images.

Non-dieters, on the other hand, do not react to thin media images by wanting to be thinner or seeing themselves that way. They do, however. exhibit a trend toward the theorized negative contrast effect when judging their own bodies relative to those of the 
magazine models; non-dieters felt slightly (though not significantly) fatter after being shown thin, idealized body images. The identification of a large group of women who indulge a fantasy by looking at fashion and beauty magazines helps to explain why some women choose to expose themselves to media containing high "thin-ideal" content. The hazard of exposure to fashion and beauty magazines, as demonstrated in the present study, is not that the images immediately and automatically make women feel depressed and discouraged, but rather that they make vulnerable women (dieters) want to be even thinner than they ordinarily do. They sell a fantasy of a thinner, better, and happier self to vulnerable women. Dieters may think that they too can look like the models they see in the magazines, if only they were to buy that advertised product or go on a different recommended diet.

The present set of experiments found repeated evidence of self-enhancement following exposure to media-portrayed idealized body images among restrained eaters. These findings replicate and extend those of Mills (1996). who found self-enhancement among females in general. Knowing the restraint status of the individual allows one to better predict her response to exposure to thin, idealized body images in the media. Restraint status predicts differential behavioral (eating) responses to such images. and in the present set of studies also predicted differential psychological response to idealized body images. It also has been found that emphasizing demand characteristics reverses this finding and results in increased reports of depression following exposure to ads featuring thin bodies (Mills et al., 2001). Therefore, our results help to clarify the inconsistencies in previous research in this area and suggest that the mass media play a 
significant, but complicated, role in disordered eating by encouraging escapist fantasy and providing inspiration for certain women. In the long term, women for whom the tashion and beauty magazines provide enjoyment may be internalizing an increasingly unrealistic ideal body for themselves.

\section{Limitations and Directions for Future Research}

Possible limitations of the present series of studies include the strength of the media manipulation we used. We do not know whether a more powerful media manipulation (e.g.. exposing participants to an increased number of advertisements) might produce different results. However, it is imperative for research in this area to consider the balance between the power of an experimental manipulation and the minimization of implicit and explicit demand characteristics. Another limitation of these studies is a reduction of external validity because participants were looking at the ads for purposes of cooperation with an ostensible market-research study and not for enjoyment s sake.

The present series of studies provide a foundation for several lines of future research. One aim should be to provide clarification for whether restrained eaters are. in fact. the women buying and reading fashion and beauty magazines - as has been alluded to in the discussion sections. Stice et al. (1994) have shown a relation between media usage and eating disorder symptomatology. They. and other researchers, have used this relation to support the sociocultural model of eating disorders: that media use causes eating disordered symptoms. However, another possible conclusion pointed out in the introduction is that women who display eating disorder symptoms are the ones who enjoy 
reading such media. This alternative conclusion is supported by the finding of selfenhancement among restrained eaters, who score higher on indices of eating disorder symptomatology than do unrestrained eaters, following exposure to thin media images. It would lend further support to the inspiration hypothesis to demonstrate that restrained eaters are the ones choosing to buy and read women's fashion and beauty magazines.

As was reviewed in the introduction, much attention has been paid to the sociocultural pressure women are under to diet. However, an equally interesting question is what stops women from dieting in the face of this pressure. The present findings found that unrestrained eaters feel worse about themselves after looking at thin media images. If exposure to ubiquitous media images makes them feel fat, why don't they diet?

Another aim for future research should be to examine the relation between mood and seif-perception. The studies presented here, as well as others (e.g., Irving. 1990). found effects of media exposure on self-perception but not affect. Implications for body-image theory should be further examined.

Another aim for future research is to examine exactly why dieters overeat in response to thin media images and for the long-term effects of exposure to fashion and beauty magazines on dieters' eating disorder symptomatology. Although there are differences between restrained eaters and eating disordered populations, the disinhibiting effects of media exposure have clinical implications for treatment of binge eating. Recovering eating-disordered patients may well be advised. for instance, to avoid such materials in an effort to refrain from symptomatic behaviour. 
The chief finding of self-enhancement among restrained eaters following exposure to idealized body images is intriguing, counterintuitive, and answers many important questions largely ignored by previous researchers. The results found in the present set of studies could provide an excellent springboard for future research aimed at uncovering what benefit women derive (if any) from going out of their way to expose themselves to impossible standards for weight and shape. 


\section{References}

American Psychological Association. (1992). Ethical principles of psychologists and code of conduct. American Psychologist, 47, 1597-1611.

Andersen. A.E., \& DiDomenico, L. (1992). Diet vs. shape content of popular male and female magazines: A dose-response relationship to the incidence of eating disorders? International Joumal of Eating Disorders, 11, 283-287.

Anderson, S.M. \& Bem, S.L. (1981). Sex typing and androgyny in dyadic interaction: Individual differences in responsiveness to physical attractiveness. Journal of Personality and Social Psychology, 41, 74-86.

Atkinson, C. \& Polivy, J. (1976). Effects of delay and attack and retaliation on state depression and hostility. Journal of Abnormal Psychology, 85, 570-576.

Barber, N. (1998). Secular changes in standards of bodily attractiveness in women: Tests of a reproductive model. International Journal of Eating Disorders. 23. $449-453$.

Borzekowski, D.L.G, Robinson, T.N., \& Killen, J.D. (2000). Does the camera add 10 pounds? Media use, perceived importance of appearance. and weight concerns among teenage girls. Joumal of Adolescent Health, 26, 36-41.

Botta, R.A. (1999). Television images and adolescent girls' body image disturbance. Journal of Communication, 49, 22-41.

Cash, T.F., Cash, D.W., \& Butters, J.W. (1983). "Mirror, mirror, on the wall...?": Contrast effects and self-evaluations of physical attractiveness. Personality and Social Psychology Bulletin, 9, 351-358. 
Collins, R.L. (1996). For better or worse: The impact of upward social comparison on self-evaluations. Psychology Bulletin, 119, 51-69.

Cools. J., Schotte, D.E., \& McNally, R.J. (1992). Emotional arousal and overeating in restrained eaters. Journal of Abnormal Psychology, $101,348-351$.

Cusumano, D.L., \& Thompson. J.K. (1997). Body image and body shape ideals in magazines: Exposure, awareness, and internalization. Sex Roles, 37, 701-721.

Fallon. A.. \& Rozin, P. (1985). Sex differences in perceptions of desirable body shape. Journal of Abnormal Psychology, 94, 102-105.

Festinger, L. (1954). A theory of social comparison processes. Human Relations. 7, 117-140.

Fouts, G. \& Burggraf, K. (1999). Television situation comedies: Female body images and verbal reinforcements. Sex Roles, $40,473-481$.

Garner, D.M. \& Garfinkel, P.E. (1982). The multidetermined nature of anorexia nervosa. In P.E. Garfinkel and D.M. Garner (Eds.), Anorexia nervosa: A multidimensional perspective. New York: Brunner-Mazel.

Garner, D.M., Garfinkel, P.E., Schwartz, D., \& Thompson, M. (1980). Cultural expectations of thinness in women. Psychological Reports, 47, 483-491.

Garner, D.M., Olmsted, M.P., \& Polivy. J. (1983). The development and validation of a multidimensional eating disorder inventory for anorexia nervosa and bulimia. International Journal of Eating Disorders, $2,15-34$. 
Gordon, R.A. (1988). A sociocultural interpretation of the current epidemic of eating disorders. In B.J. Blinders, B.F. Chaiting, \& R. Goldstein (Eds.). The Eating Disorders. Great Neck. NY: PMA.

Hamilton, K. \& Waller, G. (1993). Media Influences on body size estimation in anorexia and bulimia: An experimental study. British Journal of Psychiatry, 162, 837. 840.

Harrison, K. \& Cantor, J. (1997). The relationship between media consumption and eating disorders. Journal of Communication. 47, 40-67.

Heatherton, T.F.. \& Baumeister, R.F. (1991). Binge eating as escape from selfawareness. Psychological Bulletin, 110, 86-108.

Heatherton, T.F. \& Polivy, J. (1991). Development and validation of a scale for measuring state self-esteem. Journal of Personality and Social Psvchology, 60, $313-j 21$. Heatherton, T.F. \& Polivy, J. (1994). Chronic Dieting and Eating Disorders: A Spiral Model. In J.H. Crowther. S.E. Hobfall. M.A.P. Stephens. \& D.L. Tennenbaum (Eds.), The etiology of bulimia: The individual and familial context. Washington, DC: Hemisphere Publishers.

Heinberg, L.J. \& Thompson, J.K. (1995). Body image and televised images of thinness and attractiveness: A controlled laboratory investigation. Journal of Social and Clinical Psychology, 14, 325-338.

Henderson-King, E. \& Henderson-King, D. (1997). Media effects on women's body esteem: Social and individual difference factors. Journal of Applied Social Psychology, 27, 399-417. 
Helson. H. (1964). Adaptation-level theory: An experimental and systematic approach to behavior. New York: Harper \& Row.

Irving, L.M. (1990). Mirror images: Effects of the standard of beauty on the selfand body-esteem of women exhibiting varying levels of bulimic symptoms. Journal of Social and Clinical Psychology, 9, 230-242.

Kendler, K.S., MacLean, C., Neale, M., Kessler, R., Heath, A.. \& Eaves, L. (1991). The genetic epidemiology of bulimia nervosa. American Journal of Psychiatry, 148, 1627-1637.

Kenrick, D.T. \& Gutierres, S.E. (1980). Contrast effects and judgements of physical attractiveness: When beauty becomes a social problem. Journal of Personality and Social Psychology, 38, 131-140.

Lockwood, P. \& Kunda, Z. (1997). Superstars and me: Predicting the impact of role models on the self. Journal of Personality and Social Psychology, 73, 91-103.

Martin. M.C. \& Kennedy, P.F. (1993). Advertising and social comparison: Consequences for female preadolescents and adolescents. Special Issue: The pursuit of beauty. Psychology and Advertising, 10, 513-530.

McCabe, R.E., McFarlane, T.L., Polivy, J., \& Olmsted, M.P. (2001). Eating disorders, dieting, and the accuracy of self-reported weight. International Journal of Eating Disorders, 29, 59-64.

McFarlane, T., Polivy, J., \& Herman, C.P. (1998). Effects of false weight feedback on mood, self-evaluation, and food intake in restrained and unrestrained eaters. Journal of Abnormal Psychology, 107, 312-318. 
Mills, J.S. (1996). The effects of exposure to media-portrayed idealized body images on self-evaluation in women. Unpublished Master's thesis.

Mills, J.S., McCabe. R.E.. \& Polivy, J. (1999). Exploding the myth: Dieting makes you happier. Healthy Weights Journal, 13, 9-11.

Mills, J.S., Polivy, J., \& Herman. C.P. (1998). The real relationship between mass media and women's body image. Manuscript in preparation.

Mills, J.S., Polivy, J.. Herman. C.P.. \& Tiggemann, M. (2001). Exposure to thin media images: Evidence of self-enhancement among restrained eaters. Manuscript submitted for publication.

Mintz, L.B. \& Betz, N.E. (1988). Prevalence and correlates of eating disordered behaviors among undergraduate women. Journal of Counseling Psychology, 35. 463 471.

Murray, S. (1999). Eating disorders and criticism of cultural ideals. European Eating Disorders Review, 7, 204-212.

Myers, P.N. \& Biocca, F.A. (1992). The elastic body image: The effect of television advertising and programming on body image distortions in young women. Joumal of Communication, 42, 108-133.

Ogden, J. \& Mundray, K. (1996). The effect of the media on body satisfaction: The role of gender and size. European Eating Disorders Review, 4, 171-182.

Polivy, J., \& Herman, C.P. (1995). Dieting and its relation to eating disorders. In K.D. Brownell \& C.G. Fairburn (Eds.), Eating Disorders and Obesity: A Comprehensive Handbook. New York: Guilford. 
Polivy, J, Herman, C.P. \& Howard, K. (1988). The Restraint Scale: Assessment of dieting. In M. Hersen \& S. Bellack (Eds.), Dictionary of Behavioural Assessment Techniques, (377-380). New York: Pergamon.

Posavac, H.D., Posavac. S.S., \& Posavac, E.J. (1998). Exposure to media images for female attractiveness and concern with body weight among young women. Sex Roles, 38, 187-201.

Pyle, R.L., Halvorson, P.A., Neuman, P.A., \& Mitchell, J.E. (1986). The increasing prevalence of bulimia in freshman college students. International Journal of Eating Disorders, 5, 631-647.

Richins, M.L. (1991). Social comparison and the idealized images of advertising. Journal of Consumer Research, 18, 71-83.

Seddon. L.. \& Berry, N. (1996). Media-induced disinhibition of dietary restraint. British Joumal of Health Psychology, 1, 27-33.

Silverstein, B., Perdue, L., Peterson, B., \& Kelly, E. (1986). The role of the mass media in promoting a thin standard of bodily attractiveness for women. Sex Roles. 14. $519-532$.

Singh, D. (1994). Ideal female body shape: Role of body weight and waist-to-hip ratio. International Journal of Eating Disorders, 16, 283-288.

Snow, J.T. \& Harris, M.B. (1986). An analysis of weight and diet content in tive women's interest magazines. The Journal of Obesity and Weight Regulation, $5,194-214$. 
Spitzer, B.L., Henderson, K.A., \& Zivian, M.T. (1999). Gender differences in population versus media body sizes: A comparison over four decades. Sex Roles. 40 , 545-565.

Sporkin, E. (2001, May 14). The 50 Most Beautiful People: Catherine ZetaJones. People Weekly, 55, 82-83. New York: Time Inc.

Stice, E., Schupak-Neuberg, E., Shaw, H.E.. \& Stein, R.I. (1994). Relation of media exposure to eating disorder symptomatology: An examination of mediating mechanisms. Journal of Abnormal Psychology, 103, 836-840.

Stice, E. \& Shaw. H.E. (1994). Adverse effects of the media portrayed thin-ideal on women and linkages to bulimic symptomatology. Journal of Social and Clinical Psychology, 13, 288-308.

Strauss, J., Doyle, A.E., \& Kreipe, R. (1994). The paradoxical effect of diet commercials on reinhibition of dietary restraint. Journal of Abnormal Psychology, 103, $441-444$.

Striegel-Moore, H. (1993). Etiology of binge eating: A developmental perspective. In C.G. Fairburn \& G.T. Wilson (Eds.), Binge eating: Nature, assessment and treatment. New York: Guilford Press, 144-172.

Striegel-Moore, R.H., Silberstein, L.R., \& Rodin. J. (1986). Toward an understanding of risk factors for bulimia. American Psvchologist, 41, 246-263.

Szmukler, G., McCance, C., McCrone, L., \& Hunter, D. (1986). Anorexia nervosa: A psychiatric case register study from Aberdeen. Psychological Medicine, 16. 49-58. 
Tesser, A. (1988). Toward a self-evaluation maintenance model of social behavior. In L. Berkowitz (Ed.), Advances in experimental social psychology (Vol. 21. pp. 181-227). New York: Academic Press.

Thorton, B. \& Moore, S. (1993). Physical attractiveness contrast effect: Implications for self-esteem and evaluations of the social self. Personality and Social Psychology Bulletin, 19, 474-480.

Tiggeman, M., \& Pickering, A.S. (1996). Role of television in adolescent women's body dissatisfaction and drive for thinness. International Journal of Eating Disorders, 20, 199-203.

Waller, G., Hamilton, K., \& Shaw, J. (1992). Media influences on body size estimation in eating disordered and comparison subjects. British Review of Bulimia and Anorexia Nervosa, 6, 81-87.

Wilson, G.T., \& Eldredge, K.L. (1992). Pathology and development of eating disorders: Implications for athletes. In K.D. Brownell, J. Rodin, \& J.H. Wilmore (Eds.). Eating, body weight, \& performance in athletes: Disorders of modern society (pp. 115 127). Philadelphia: Lea \& Febiger.

Wiseman, M.A., Gray, J.J., Mosimann, J.E.. \& Ahrens, A.H. (1992). Cultural expectations of thinness in women: An update. International Journal of Eating Disorders, 11. 85-89. 


\section{Tables}

Table 1

Mean Appearance State Self-Esteem. Current and Ideal Body-Size Perceptions, and Intake (with standard errors in parentheses) as a Function of Restraint and Ad Type.

\section{Ad Type}

Thin bodies Large bodies Product-only

Restrained eaters

$\begin{array}{llll}\text { Appearance self-esteem } & 19.00(1.37) & 15.70(1.37) & 17.95(.78) \\ \text { Current body size perception } & 3.92(.30) & 4.80(.34) & 4.53(.29) \\ \text { Ideal body size } & 2.65(.15) & 3.30(.21) & 3.37(.19) \\ \text { Intake (grams) } & 85.92(11.60) & 46.80(8.22) & 63.84(6.86) \\ \underline{\mathbf{n}} & 13 & 10 & 19\end{array}$

Unrestrained eaters

\begin{tabular}{llll} 
Appearance self-esteem & $20.00(1.37)$ & $22.53(.97)$ & $21.00(.96)$ \\
Current body size perception & $3.83(.19)$ & $3.17(.30)$ & $3.21(.18)$ \\
Ideal body size & $3.03(.18)$ & $2.83(.21)$ & $2.96(.12)$ \\
Intake (grams) & $56.07(8.06)$ & $69.40(9.61)$ & $61.42(5.07)$ \\
$\underline{\mathrm{n}}$ & 15 & 15 & 26 \\
\hline
\end{tabular}


Table 2

Mean Anxiety, Depression, Total Negative Affect, Appearance State Self-Esteem, and Current and Ideal Body-Size Perceptions (with standard errors in parentheses) as a Function of Thinness-Attainability Beliefs, and Ad Type among Restrained Eaters.

\begin{tabular}{|c|c|c|}
\hline & Ad & Type \\
\hline & Thin bodies & Product-only \\
\hline \multicolumn{3}{|l|}{ High Thinness Attainability } \\
\hline Anxiety & $27.4(2.67)$ & $34.00(2.67)$ \\
\hline Depression & $25.90(2.26)$ & $34.20(2.26)$ \\
\hline Total negative affect & $86.6(6.82)$ & $106.10(6.82)$ \\
\hline Appearance state self-esteem & $19.10(1.25)$ & $15.80(1.25)$ \\
\hline Current body size & $4.20(.23)$ & $4.25(.27)$ \\
\hline Ideal body size & $2.95(.16)$ & $2.75(.19)$ \\
\hline$\underline{\mathrm{n}}$ & 10 & 10 \\
\hline \multicolumn{3}{|l|}{ Low Thinness Attainability } \\
\hline Anxiety & $35.90(2.67)$ & $30.00(2.67)$ \\
\hline Depression & $30.80(2.26)$ & $26.10(2.26)$ \\
\hline Total negative affect & $103.70(6.82)$ & $89.90(6.82)$ \\
\hline Appearance state self-esteem & $16.60(1.25)$ & $18.60(1.25)$ \\
\hline Current body size & $4.25(.27)$ & $4.30(.32)$ \\
\hline Ideal body size & $3.10(.22)$ & $2.90(.18)$ \\
\hline$\underline{\mathbf{n}}$ & 10 & 10 \\
\hline
\end{tabular}


Neutral Thinness Attainability

$\begin{array}{lll}\text { Anxiety } & 32.09(2.84) & 30.60(2.21) \\ \text { Depression } & 26.45(1.63) & 28.50(2.63) \\ \text { Total negative affect } & 92.18(5.46) & 98.50(7.89) \\ \text { Appearance state self-esteem } & 18.18(1.10) & 19.20(1.34) \\ \text { Current body size } & 3.36(.17) & 4.15(.33) \\ \text { Ideal body size } & 2.64(.19) & 3.00(.22) \\ \underline{\mathrm{n}} & 11 & 10\end{array}$


Table 3

Number of Participants Requesting Participation in Diet Program as a Function of Ad

Type and Restraint.

\begin{tabular}{|c|c|c|}
\hline Restraint Status & Ad & Type \\
\hline Diet Program & Thin bodies & Product-only \\
\hline \multicolumn{3}{|l|}{ Restrained } \\
\hline Lenient & 2 & 2 \\
\hline Moderate & 3 & 2 \\
\hline$\underline{\text { Strict }}$ & 1 & 2 \\
\hline$\underline{\mathbf{n}}$ & 11 & 11 \\
\hline \multicolumn{3}{|l|}{ Unrestrained } \\
\hline Lenient & 2 & 2 \\
\hline Moderate & 3 & 3 \\
\hline$\underline{\text { Strict }}$ & 0 & 0 \\
\hline$\underline{\mathbf{n}}$ & 11 & 12 \\
\hline
\end{tabular}


Table 4

Mean Appearance State Self-Esteem, and Current and Ideal Body-Size Perceptions (with standard errors in parentheses) as a Function of Threat Condition and Restraint.

\begin{tabular}{lll}
\hline Restraint Status & \multicolumn{1}{c}{ Threat } & Condition \\
\hline Restrained & $\underline{\text { Threat }}$ & $\underline{\text { No-Threat }}$ \\
Appearance self-esteem & $19.22(1.46)$ & $15.80(1.50)$ \\
Current Body Size & $3.95(.31)$ & $5.55(.47)$ \\
Ideal Body Size & $2.70(.11)$ & $3.50(.39)$ \\
n & 10 & 10 \\
Unrestrained & & \\
Appearance self-esteem & $21.00(1.68)$ & $21.50(1.18)$ \\
Current Body Size & $3.50(.32)$ & $3.58(.31)$ \\
Ideal Body Size & $3.04(.17)$ & $2.96(.18)$ \\
n & 12 & 12 \\
\hline
\end{tabular}


Table 5

Number of Participants Requesting Participation in a Diet Program as a Function of

Threat Condition and Restraint.

\begin{tabular}{lll}
\hline Restraint Status & Threat & Condition \\
\hline Diet Program & Threat & No-Threat \\
Restrained & & \\
Lenient & 1 & 3 \\
Moderate & 5 & 2 \\
Strict & 0 & 3 \\
n & 10 & 10 \\
Unrestrained & & \\
Lenient & 2 & 2 \\
$\underline{\text { Moderate }}$ & 3 & 1 \\
$\underline{\text { Strict }}$ & 0 & 0 \\
$\underline{\text { n }}$ & 11 & 12 \\
\hline
\end{tabular}

